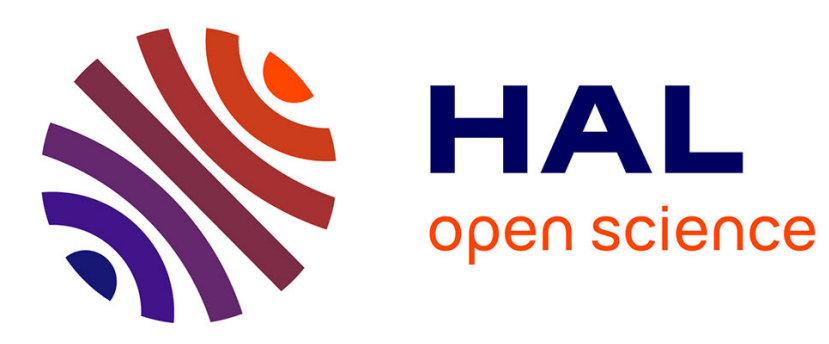

\title{
Quantitative calorimetric analysis of the fretting damage: Construction of the elastic shakedown boundary
}

Abdel-Rahman Moustafa, Bruno Berthel, Siegfried Fouvry, Eric Charkaluk

\section{- To cite this version:}

Abdel-Rahman Moustafa, Bruno Berthel, Siegfried Fouvry, Eric Charkaluk. Quantitative calorimetric analysis of the fretting damage: Construction of the elastic shakedown boundary. International Journal of Fatigue, 2017, 95, pp.143-155. 10.1016/j.ijfatigue.2016.10.018 · hal-01522935

\section{HAL Id: hal-01522935 \\ https://hal.science/hal-01522935}

Submitted on 15 May 2017

HAL is a multi-disciplinary open access archive for the deposit and dissemination of scientific research documents, whether they are published or not. The documents may come from teaching and research institutions in France or abroad, or from public or private research centers.
L'archive ouverte pluridisciplinaire HAL, est destinée au dépôt et à la diffusion de documents scientifiques de niveau recherche, publiés ou non, émanant des établissements d'enseignement et de recherche français ou étrangers, des laboratoires publics ou privés. 
A.R. Moustafa, B. Berthel, S. Fouvry, E. Charkaluk, International Journal of Fatigue, 2017, 95, 143.

\title{
QUANTITATIVE CALORIMETRIC ANALYSIS OF THE FRETTING DAMAGE: CONSTRUCTION OF THE ELASTIC SHAKEDOWN BOUNDARY
}

\author{
$\underline{\text { A.R. Moustafa }}{ }^{1}$, B. Berthel ${ }^{1}$, S. Fouvry ${ }^{1}$ and E. Charkaluk ${ }^{2}$ \\ ${ }^{1}$ LTDS, Ecole Centrale de Lyon, 36 Avenue Guy de Collongue, Ecully 69134 Cedex, France. abdel- \\ rahman.moustafa@ec-lyon.fr, bruno.berthel@ec-lyon.fr, siegfried.fouvry@ec-lyon.fr \\ ${ }^{2}$ LML, Ecole Centrale de Lille, Boulevard Paul Langevin, 59655 Villeneuve d'Ascq Cedex, France. \\ eric.charkaluk@ec-lille.fr
}

Corresponding author: A. R. Moustafa (Tel: +33 (0)4 721860 44; E-mail:

abdel.moustaf@gmail.com; bruno.berthel@ec-lyon.fr)

ABSTRACT. The paper aims to illustrate the relevant use of infrared thermography and energy based approaches to study the plastic behavior and the crack initiation under plain fretting loadings. A well known 35Ni Cr Mo 16 low-alloyed steel was studied under various plain fretting partial slip conditions. The experimental results showed that the proposed $2 D$ image processing method is able to estimate thermoelastic amplitude fields in a good agreement with the theory of linear thermoelasticity, and mean intrinsic dissipation per cycle fields reflecting localized microplastic deformation. The maximal local evolution of the intrinsic dissipation as function of the shear stress amplitude, underlined the presence of a non-dissipative regime, where the specimen mainly undergoes elastic deformation and a dissipative regime where plastic deformation take place. The transition between these two regimes was then coupled with the local elastic shakedown boundary.

KEYWORDS. Fretting; Crack nucleation; Thermography; Heat sources; Thermoelasticity; Dissipation; Plasticity; Damage.

\section{NOMENCLATURE}

$R$
$P$
$p(x)$
$p_{\max }$
$a$
$a_{m}$
$c_{m}$
$b$
$\delta$
$\delta^{*}$
$Q$
$Q^{*}$
$q(x)$

Cylinder radius

Static normal force

Hertz contact pressure distribution

Maximal Hertzian pressure

Hertzian contact half size

Measured contact half size

Measured stick zone half size

Projected crack length

Cyclic relative displacement

Cyclic relative displacement amplitude

Macroscopic tangential force

Macroscopic tangential force amplitude

Classical shear stress distribution 
A.R. Moustafa, B. Berthel, S. Fouvry, E. Charkaluk, International Journal of Fatigue, 2017, 95, 143.

\begin{tabular}{|c|c|}
\hline$q_{\max }$ & Maximal value of $q(x)$ reach during a cycle \\
\hline$E$ & Young modulus \\
\hline$\sigma_{\mathrm{u}}$ & Ultimate stress \\
\hline$\sigma_{\mathrm{y} 0.2}$ & Yield stress at $0.2 \%$ \\
\hline$v$ & Poisson ratio \\
\hline$T$ & Absolute temperature \\
\hline$\varepsilon$ & Small strain tensor \\
\hline$\alpha_{j}$ & $\begin{array}{l}\text { The components of a vector } \alpha \text { of } n-1 \text { internal } \\
\text { variables describing the thermodynamic state }\end{array}$ \\
\hline$f_{a}$ & Camera frame rate \\
\hline$\rho$ & Mass density \\
\hline$C$ & Specific heat \\
\hline$\psi$ & Helmholtz free energy \\
\hline$K$ & Thermal conductivity tensor \\
\hline$k$ & Thermal conductivity constant \\
\hline$d_{1}$ & Intrinsic dissipation \\
\hline$S_{\text {the }}$ & Thermomechanical coupling sources \\
\hline$s_{i c}$ & Internal coupling sources \\
\hline$r_{\text {ext }}$ & Volumetric heat sources of external origins \\
\hline$T_{0}$ & System equilibrium temperature \\
\hline$\theta=T-T_{0}$ & Temperature variations \\
\hline$\theta(x, y, t)$ & Specimen surface temperature variations \\
\hline$\tau_{t h}^{2 D}$ & $\begin{array}{l}\text { Time constant representing heat loss by convection } \\
\text { and radiation between the specimen surfaces and the } \\
\text { surroundings }\end{array}$ \\
\hline$h$ & Heat transfer coefficient \\
\hline$\sigma_{a}$ & Stress amplitude tensor \\
\hline$f(t)$ & Periodic time function \\
\hline$\lambda$ & Thermal expansion coefficient \\
\hline$w_{\text {the }}$ & Thermoelastic energy \\
\hline$\Gamma$ & Cycle period \\
\hline$N$ & Number of cycles \\
\hline$f_{L}$ & Loading frequency \\
\hline$f_{a}$ & Camera frame rate \\
\hline$\theta_{f i t}(x, y, t)$ & Temperature approximation function \\
\hline$P_{\alpha}$ & Polynomials in $x$ and $y$ \\
\hline$N_{x}$ & Smoothing window half-size according to $x$ direction \\
\hline$N_{y}$ & Smoothing window half-size according to $x$ direction \\
\hline$N_{t}$ & Smoothing window half-size according to time, $t$ \\
\hline$\Delta x$ & Spatial resolution \\
\hline$\sigma_{C r}$ & Crossland equivalent stress \\
\hline$\sqrt{J_{2, a}}$ & $\begin{array}{l}\text { Square root of the maximum amplitude of the second } \\
\text { stress invariant }\end{array}$ \\
\hline$\underline{\underline{S}}$ & Deviatoric stress \\
\hline
\end{tabular}


A.R. Moustafa, B. Berthel, S. Fouvry, E. Charkaluk, International Journal of Fatigue, 2017, 95, 143.

$$
\begin{aligned}
& P_{H, \max } \\
& \tau_{d} \\
& \sigma_{d} \\
& \Delta q_{l o c}
\end{aligned}
$$

Maximum value of the hydrostatic pressure throughout the history of the stress

Alternating shear fatigue limit

Alternating bending fatigue limit

Cyclic microplasticity threshold

\section{INTRODUCTION}

Fretting, defined as oscillating contacts, of very small amplitudes can be considered as the worst case scenario introducing strong and heterogeneous stress gradients states in structures. Fretting damage has been recognized as a major problem in several industrial applications (helicopters, aircraft, trains, ships...) [1]-[3] and continue to require attention in a variety of important studies. Under partial slip conditions, a part of the contact zone remains stuck and the fretting damage is mainly characterized by the initiation of cracks. In order to describe this damaging process, a synthetic form of a fretting mapping is used [4]. This map defines two domains: the no cracks nucleated and the cracks nucleated. Experimentally, these maps are obtained by destructive methods [5] which are time and material consuming and give scattered results.

Theoretically, current approaches to predicting crack initiation are based on the calculation of the subsurface stress field from an elastic analysis. Then applying multiaxial fatigue criteria coupled with non-local approaches to account for the severe stress gradient states imposed by the contact [3], [6], [7]. However, plasticity plays an important role in the damage process, specially at the early stages of crack growth [8]-[10]. Still the mechanics of plastic deformation near the contact interface is poorly understood.

Recently, there have been attempts to include plasticity in contact analysis. For example, authors like Ambrico and Begley in [11][12] and Alquezar et. al in [13] proposed computed Shakedown maps and cyclic plastic strain behavior maps based on the evolution of the material elasto-plastic behavior. These works highlights the complexity of the studied phenomena and maps out major regions of response behavior.

Because of the lake of experimental data in support of the wide range of contact fatigue life models, the present paper underline the relevant use of thermographic measurement to measure the onset of local plasticity accompanying fretting.

Generally, fretting is accompanied with temperature variations that may present low order of magnitudes and are often neglected by scientists. Nevertheless, no matter how small these variations are, they may correspond to amounts of heat that cannot be neglected in the energy balance.

The nature of the heat sources depends on the material behavior. They may represent an intrinsic dissipation of energy (frictional heating, plasticity, viscosity, damage, etc.), or result from thermomechanical coupling mechanisms (thermoelasticity, solid-solid phase transition, etc.). These experimental facts, are, of great interest since they characterize the irreversibility of deformation mechanisms and reveals the thermal sensitivity of the material. The importance of such energy approach is in its ability to unify microscopic and macroscopic data to facilitate the detection of damage [14]-[17].

Nevertheless, the exact mechanism of frictional heating and its origins is still considered unsolved. Some authors like Landman in [18], consider that these processes occurs by atomic-scale interactions within the top several atomic layers of the contacting surfaces, while others, like 
A.R. Moustafa, B. Berthel, S. Fouvry, E. Charkaluk, International Journal of Fatigue, 2017, 95, 143.

Rigney and Hirth in [19], believes that most energy dissipation occurs by plastic deformation processes. The issue of frictional heating was discussed in one of our previous works [20], where frictional heating in the sliding areas was modeled under partial slip conditions and found to be negligible compared to what was measured experimentally. The paper then introduce a new empirical methodology for rapid determination of crack nucleation thresholds under fretting loadings.

In light of these encouraging results, in this paper, a quantitative calorimetric analysis of the fretting damage is proposed. The heat sources are derived from thermal images using a local expression of the heat diffusion equation. A specific 2D image processing technique is then introduced to separately estimate the dissipated energy associated with irreversible microstructural transformations and the thermoelastic coupling induced by the reversible thermal sensitivity of the material. The maximal local evolution of the intrinsic dissipation as function of the maximal shear stress is then coupled with the onset of micro-plastic phenomena responsible of the fretting damage. Finally, these results were used to build the elastic shakedown boundary.

\section{MATERIALS}

The present study was performed on a 35Ni Cr Mo 16 low-alloyed steel in a cylinder on flat contact configuration. The $35 \mathrm{Ni} \mathrm{Cr}$ Mo 16 is a high strength, low alloy vacuum arc melted steel that takes its name from French industry designation. The combination of high strength, toughness and superior cleanliness available with the $35 \mathrm{Ni} \mathrm{Cr}$ Mo 16 steel identifies it as a good candidate for many industrial applications. Cylindrical pads are made from a heat treated steel alloy $100 \mathrm{Cr} 6$, presenting same elastic properties as the $35 \mathrm{Ni} \mathrm{Cr}$ Mo 16 but higher mechanical strength to ensure that cracks initiate only in flat pads. The mechanical properties of the studied materials are presented in Table 1.

\begin{tabular}{|c|c|c|c|c|}
\hline Material & $E(\mathrm{MPa})$ & $v$ & $\sigma_{u}(\mathrm{MPa})$ & $\sigma_{y 0.2 \%}(\mathrm{MPa})$ \\
\hline 35Ni Cr Mo 16 & 200 & 0.3 & 1130 & 810 \\
\hline 100 Cr 6 & 195 & 0.3 & 1500 & 813 \\
\hline
\end{tabular}

Table 1: Mechanical properties of the studied materials.

The 35Ni Cr Mo 16 steel used for this work, is well characterized by our research team, and, an important data base on the cracking conditions already exist [21]. It also present good and homogeneous thermal properties. The thermo-physical data commonly used for steel materials, and used for this work, are presented in Table 2.

\begin{tabular}{|c|c|c|c|}
\hline $\begin{array}{c}\rho \\
\left(k g \cdot m^{-3}\right)\end{array}$ & $\left(J \cdot \mathrm{Kg}^{-1} \cdot{ }^{\circ} \mathrm{C}^{-1}\right)$ & $\left(\mathrm{W} \cdot \mathrm{m}^{-1} \cdot{ }^{\circ} \mathrm{C}^{-1}\right)$ & $\left(10^{-6} \cdot \mathrm{K}^{-1}\right)$ \\
\hline 7800 & 460 & 60 & 1 \\
\hline
\end{tabular}

Table 2: Thermo-physical properties commonly used for steels.

The different experimental conditions are illustrated in Table 3. 
A.R. Moustafa, B. Berthel, S. Fouvry, E. Charkaluk, International Journal of Fatigue, 2017, 95, 143.

\begin{tabular}{|c|c|}
\hline$R(\mathrm{~mm})$ & $p_{\max }(\mathrm{MPa})$ \\
\hline 80 & 1000 \\
\hline 80 & 800 \\
\hline 160 & 600 \\
\hline 160 & 400 \\
\hline
\end{tabular}

Table 3: Experimental conditions: $R$ cylinder radias and $p_{\max }$ Hertzian maximum contact pressure.

\section{EXPERIMENTAL SET-UP}

Tests were carried out using an experimental set-up specially designed at our laboratory and mounted on a servo-hydraulic machine. This set-up includes two actuators: one for the normal load and another for the cyclic tangential displacement [4].

A fretting experiment consists in applying a static normal force $P$ to the counter body (Figure 1 (a)) causing an elliptic pressure distribution, $p(x)$, over the contact zone with a maximal value, $p_{\max }$ (Figure 2 (b)). A cyclic relative displacement $\delta$, is then imposed (Figure 1 (a)) leading to a macroscopic tangential force $Q$ and a classical shear stress over the surface, $q(x)$, which exhibits its maximum value, $q_{\max }$ at the stick zone limit (Figure 2 (b)). $P, Q$ and $\delta$ are recorded during the tests and the $\delta^{*}-Q^{*}$ loop are plotted and monitored to maintain a partial slip contact conditions (Figure 2 (a)).

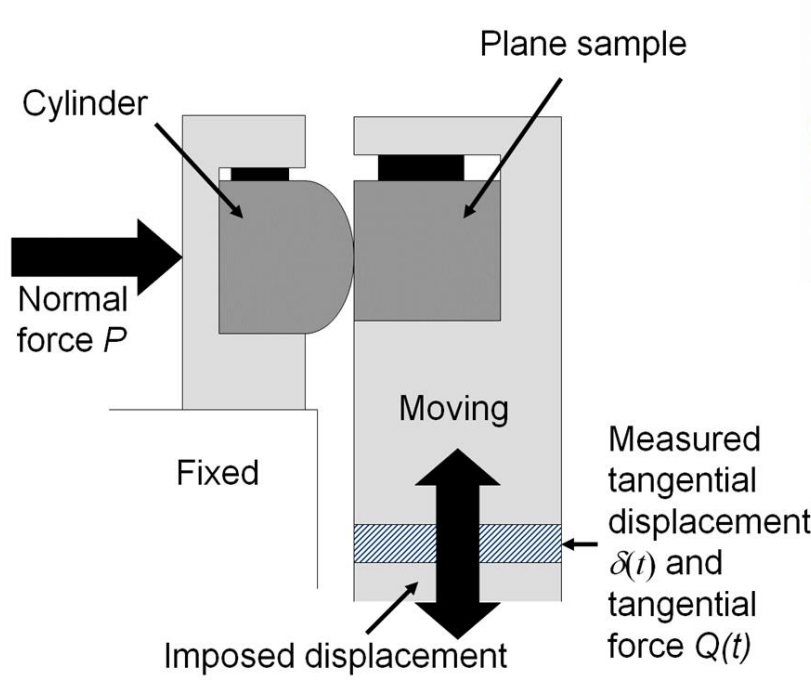

(a)

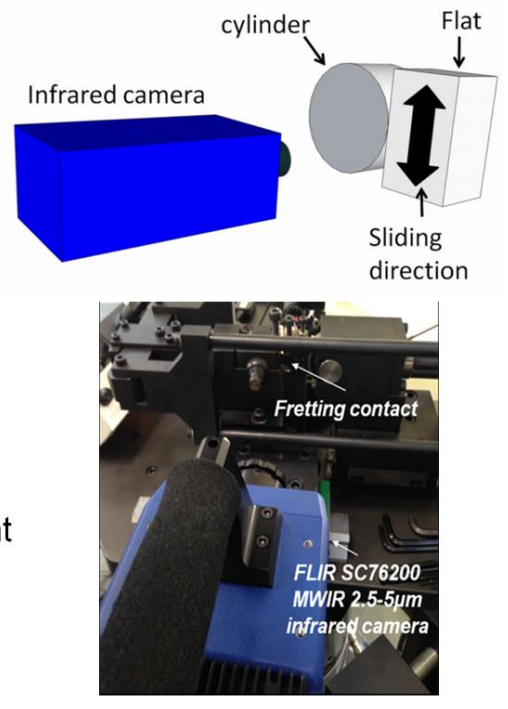

(b)

Figure 1: (a) Schematic of the fretting testing device and (b) illustration of the Infrared camera facing the contact. 


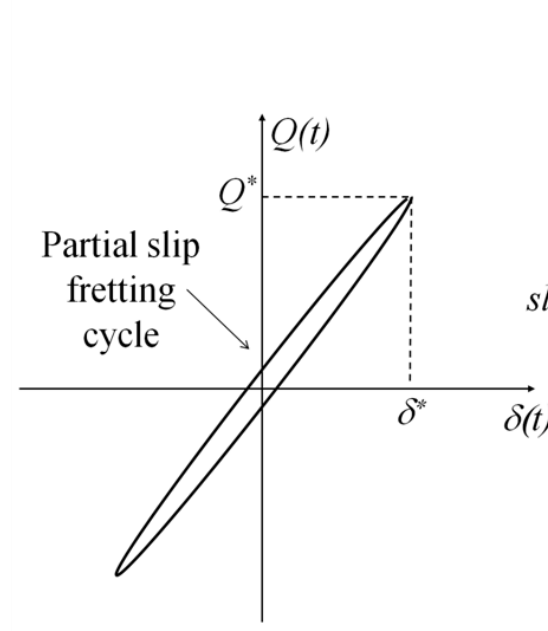

(a)

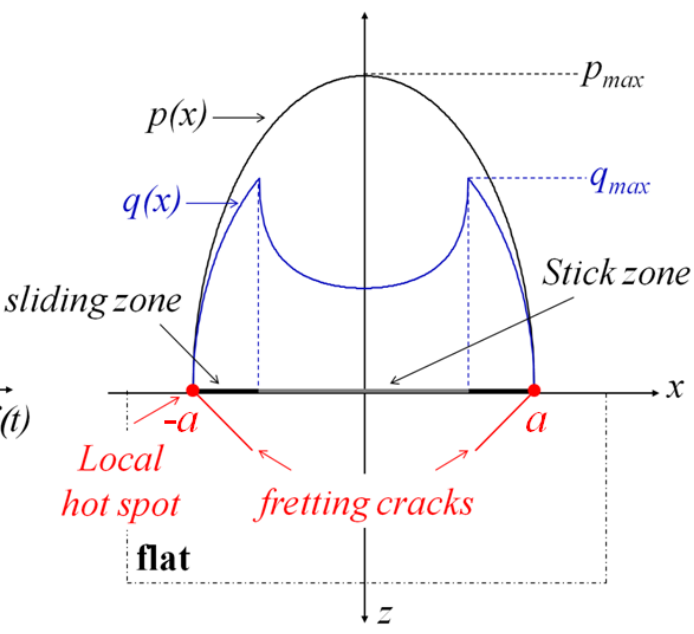

(b)

Figure 2: (a) Fretting cycle, (b) related shear, $q(x)$, and pressure, $p(x)$, distributions for a cylinder on flat contact configuration for $Q=Q^{*}$ [22].

The Infrared camera used in this study is a FLIR SC7600 MWIR 2.5-5 $\mu \mathrm{m}$. The focal length of the optical lens is $25 \mathrm{~mm}$. This camera is equipped with an InSb 640x512 element detector. The maximal frame rate, $f_{a}$, is $380 \mathrm{~Hz}$ and the noise-equivalent temperature (NET) is lower than $25 \mathrm{mK}$. In this study, the size of a pixel correspond to a zone of $95 \times 95 \mu \mathrm{m}^{2}$. The camera lens axis is then kept fixed and held perpendicular to the lateral surface of the specimens (Figure 1 (b)), and specimens were painted with a black paint to increase their emissivity. The specimen emissivity was then measured using indirect measurement of the specimen surface reflection [23] and a mean value of 0.96 was found.

The IR camera is calibrated before and after each experiment using a pixel-to-pixel calibration as in [24]. The camera spatial and temporal noise were characterized using a laboratory blackbody (SR $800 \mathrm{R}$ by CI-system) with a surface temperature accuracy of $+/-0.006{ }^{\circ} \mathrm{C}$ for $0<T<50{ }^{\circ} \mathrm{C}$ and a thermal uniformity of $+/-0.015{ }^{\circ} \mathrm{C}$.

Temporal noise corresponds to the temporal evolution of one pixel observing a constant and uniform thermal scene from the blackbody. This noise was found Gaussian with an amplitude equal to $0.02{ }^{\circ} \mathrm{C}$ (in correlation with the constructor data sheet).

Spatial noise corresponds to the amplitude of spatial fluctuations of a temperature field generated by a homogeneous thermal scene and averaged over about one hundred images. This noise was also found Gaussian with an amplitude equal to $0.19^{\circ} \mathrm{C}$.

The camera internal thermal drift was also controlled by observing the blackbody at a constant temperature and the time needed to reach a stable state was estimated to 2 hours.

Finally, in order to minimize the possible environmental effects on the thermal fields and maintain stable thermal boundary conditions, the camera and the specimens were covered with an insulation box, and experiments were carried out at room temperature. A thermocouple was also used to monitor the ambient temperature.

Vibrations and flexibility of the experimental device impose rigid body movement (rotation and translation) on the flat specimen. A marker tracking method was developed and used to eliminate these displacements as in [20] (Figure 3 (a)). This method detects markers using edge detection and basic morphology [25]. The different heat sources were then computed on a Zone Of Interest (ZOI) defined at the contact as in Figure 3 (b). 


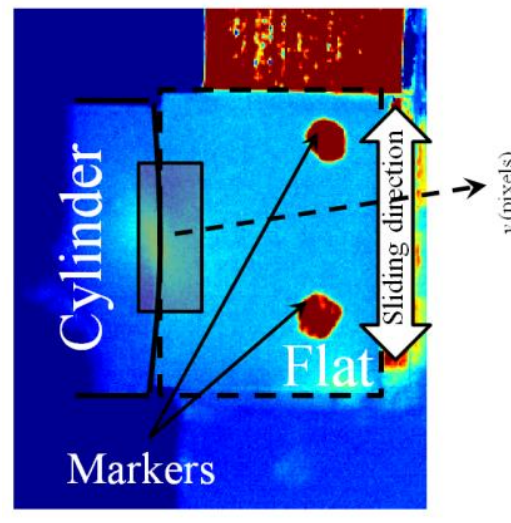

(a)

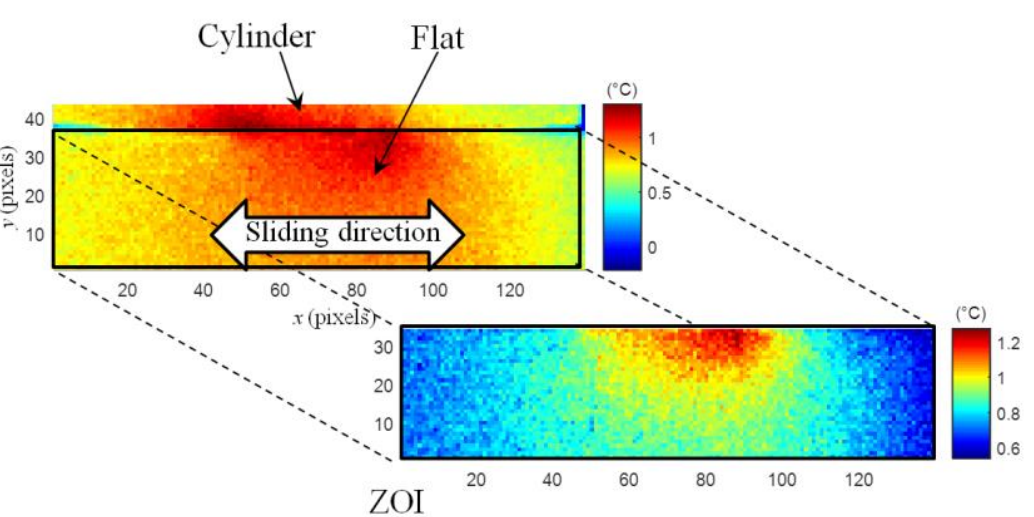

(b)

Figure 3: (a) IR image of a fretting contact showing the markers, (b) illustration of the ZOI.

\subsection{Temperature variations for constant loading parameters}

An example of temperature evolution (averaged over a ZOI equal to 30x140 pixels) during a fretting test with constant loading parameters is shown in Figure 4. It can be observed that, the thermal signal undergoes an overall thermal drift. Added to this thermal drift oscillatory variations of about $0.17{ }^{\circ} \mathrm{C}$. The overall heat generation can be divided into two phases: an unsteady state, where the averaged temperature increase from the equilibrium temperature to reach a local maximum. And a steady state, where the averaged temperature reach a stabilized and constant value $\theta_{\text {sta }}$.

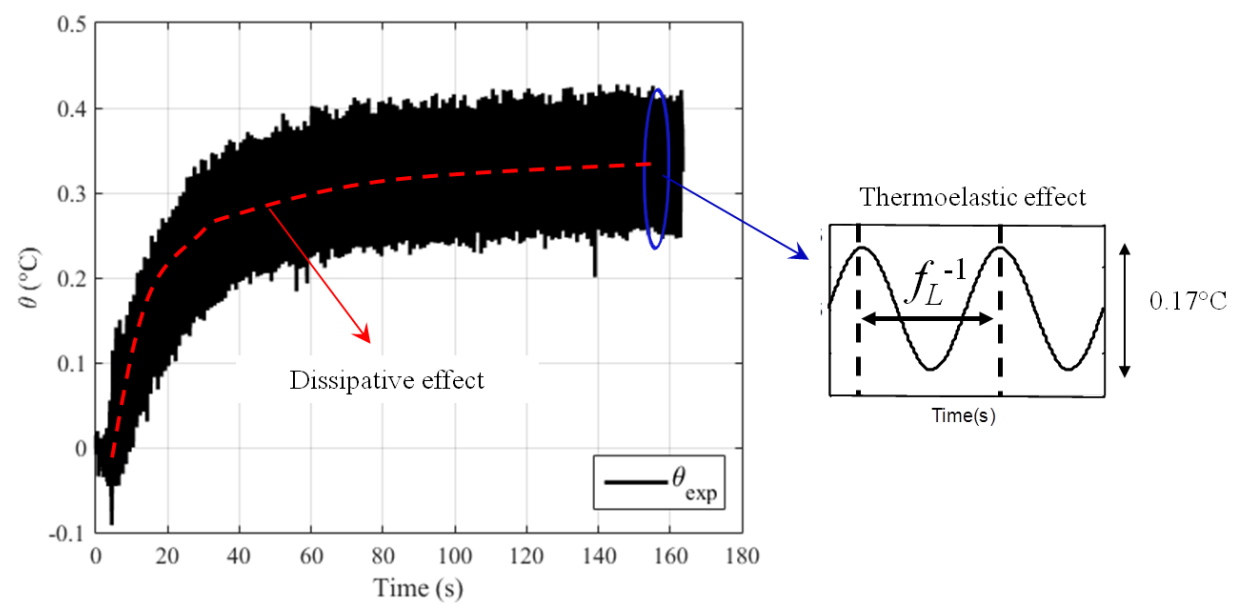

Figure 4: Temperature evolution for a fretting contact of $R=80 \mathrm{~mm}, p_{\max }=1000 \mathrm{MPa}, q_{\max }=570$

$$
\mathrm{MPa}, f_{L}=1 \mathrm{~Hz}, f_{a}=100 \mathrm{~Hz}, a=1.4 \mathrm{~mm} \text {. }
$$

\section{THERMOMECHANICAL FRAMEWORK}

In this section, we present the theoretical framework leading to the local form of the heat diffusion equation required for the estimation of the different heat sources. This approach consist on considering a fretting test as a quasi-static process mechanically and thermodynamically. This means, from a mechanical point of view, the quantities related to the acceleration in the equation of motion are neglected. From a thermodynamic point of view, the quasi-static character allows the use of the concept of local state, which is an axiomatic concept of the Thermodynamics of 
A.R. Moustafa, B. Berthel, S. Fouvry, E. Charkaluk, International Journal of Fatigue, 2017, 95, 143.

Irreversible Processes (TIP). It states that, at any point in time, the local thermodynamic quantities of a system vary in a quasi-thermostatic way despite the fact that the system is moving [26]. The TIP of near balance (or local state), provides a consistent and flexible framework to describe the behavior of materials. Its flexibility comes from the fact that one can choose a set of state variables to describe macroscopic responses of complex microstructural phenomena. The use of such framework with applications in materials modeling began to multiply in the 60s, readers interested in such approaches may refer to the works of Germain 1973 and 1974, Sidoroff 1975 and Chaboche 1978 in [26]-[29].

Since we consider a local state approach, the deformation process can be considered to be quasistatic in a thermodynamic sense. It means that any particle in the studied system, is considered as a sub-system at a thermodynamic equilibrium state. The equilibrium state of each element of materials or sub-system is then described using a set of $n+1$ state variables. The choice of these state variables is dictated by the phenomena we seek to model and the precision with which we wish to describe them. We can distinguish two types of state variables:

- The $p$, observable variables, which are $T$ the absolute temperature and $\varepsilon$ the small deformation tensor (under the assumption of small perturbations and small displacements).

- The $n+1-p$ additional variables, that in our case are represented by the $\left(\alpha_{i}\right)_{i \in\{2, \ldots, n\}}$ internal variables. These variables should have a physical sense, such as, plastic deformation $\varepsilon_{p}$ or $\varepsilon_{\mathrm{e}}$ elastic deformation, isotropic or anisotropic damage, etc., all describing the state of the material.

In the particular context of the generalized standard materials [30], the local heat diffusion equation can be written as follows by combining both first and second principles of thermodynamic :

$$
\rho C \dot{T}-\operatorname{divK}(K \overrightarrow{\operatorname{grad}}(T))=d_{1}+s_{\text {the }}+s_{\text {ic }}+r_{\text {ext }}
$$

with $\rho$ the mass density, $C=-T \psi_{\text {TT }}$ the specific heat, $\psi$ the Helmholtz free energy, $K$ the thermal conductivity tensor.

The left-hand side of Equation (1) is a differential operator applied to the temperatur, $T$, while the right-hand side the different heat sources are grouped: the intrinsic dissipation $d_{1}=\left(\sigma-\rho \frac{\partial \psi}{\partial \varepsilon}\right): \dot{\varepsilon}-\rho \frac{\partial \psi}{\partial \alpha} \cdot \dot{\alpha}$, the thermoelastic coupling sources $s_{\text {the }}=\rho T \psi_{, T, \varepsilon}: \dot{\varepsilon}$, the internal coupling sources $s_{\mathrm{ic}}=\rho T \psi_{, T, \alpha}: \dot{\alpha}$, and $r_{\text {ext }}$ representing the volumetric heat sources of external origins.

A series of hypothesis on the spatiotemporal evolutions of the sources and the temperature fields are formulated as follows [31] :

- The mass density $\rho$ and the specific heat $C$ are material constants with no variations in time.

- The material is considered as a thermally isotropic solid, meaning that the conductivity tensor can be replaced with the conductivity constant:

$$
\operatorname{div}(K \overrightarrow{\operatorname{grad}}(T))=k \cdot \operatorname{div}(\overrightarrow{\operatorname{grad}}(T))=k \nabla^{2} T
$$


A.R. Moustafa, B. Berthel, S. Fouvry, E. Charkaluk, International Journal of Fatigue, 2017, 95, 143.

- The convective derivative associated with the particular time derivative of the temperature are neglected because temperature gradients and the sliding velocity amplitudes are low:

$$
\frac{d T(\vec{x}, t)}{d t}=\frac{\partial \vec{x}}{\partial t} \cdot \overrightarrow{g r a d}(T)+\frac{\partial T}{\partial t}=\frac{\partial T}{\partial t}
$$

- The term $r_{e x t}$ is considered time independent undergoing a linear isotropic Fourier's law: $-k . \nabla^{2} T_{0}=r_{e x t}$ with $T_{0}$ the system equilibrium temperature

- Temperature variations induced by the fretting loading under partial slip conditions are low and have no influence on the microstructural state. In such context, the internal coupling is neglected $\left(s_{i c}=0\right)$ and the fatigue mechanisms are considered as purely dissipative. It is important to note, that even if we assumed that there is no coupling between temperature and microstructural variables $\left(\left(\alpha_{i}\right)_{i \in\{2, \ldots, n\}}\right)$, we did not specify the exact nature of these variables. This is why, dissipation measurements are essential in order to indentify and clarify the physical meaning of these variables.

Under those assumptions the heat diffusion equation can be written with the following form:

$$
\rho C \frac{\partial T}{\partial t}-k \nabla^{2} T=d_{1}+s_{\text {the }}-k \nabla^{2} T_{0}
$$

If we note $\theta=T-T$, the temperature variations, Eq. (4) can be written:

$$
\rho C \frac{\partial \theta}{\partial t}-k \nabla^{2} \theta=d_{1}+s_{\text {the }}
$$

On the left hand side of the above equation a linear partial differential operators are applied to the temperature, while on the right hand side, the different heat sources are grouped. In order to estimate the heat sources from equation (5) one must, first, solve an inverse and ill-posed problem and second estimate the left-hand side member of the equation from discrete noisy data. To overcome these difficulties, a regularization method is proposed in the next section.

\subsection{Heat diffusion model resolution}

The 3D heat diffusion equation (5) makes a direct link between thermal and calorimetric quantities. The idea here is to determine the heat sources in the volume of a body from the measurement of the surface temperature of this body. This type of problem falls into the category of inverse problems where it is impossible to find a single solution without a prior information on the spatial distribution of the sources.

One way to simplify this problem is to switch from a $3 \mathrm{D}$ to a $2 \mathrm{D}$ formulation of the heat diffusion model assuming that the distribution of the heat sources and consequently the temperature field are very close to the mean distribution over the sample thickness. However, the difficulty with such formulation is that the solution (the heat sources) is very sensitive to the measurement noise (experimental temperature fields). To overcome these difficulties a regularization method is proposed as follows : 
By integrating Equation (5) over the sample thickness and assuming that the specimen surface temperature, $\theta(x, y, t)$, can be compared to a mean temperature over its thickness. the following equation can be obtained [31]:

$$
\rho C\left(\frac{\partial \bar{\theta}}{\partial t}+\frac{\bar{\theta}}{\tau_{t h}^{2 D}}-\frac{k}{\rho C}\left(\frac{\partial^{2} \bar{\theta}}{\partial x^{2}}+\frac{\partial^{2} \bar{\theta}}{\partial y^{2}}\right)\right)=\overline{d_{1}}+\overline{s_{t h e}}
$$

with $\bar{\theta}, \overline{d_{1}}$ and $\overline{s_{\text {the }}}$ are respectively, the temperature variations, the intrinsic dissipation and the thermoelastic coupling averaged through the material thickness. $\tau_{t h}^{2 D}$ is a time constant representing heat loss by convection and radiation between the specimen front and back surfaces and the surroundings. It depends on the material, the specimen geometry and $h$, the heat transfer coefficient between the specimen and the surroundings. It is determined experimentally and defined as follows:

$$
\tau_{t h}^{2 D}=\frac{\rho C e}{2 h}
$$

Note that the division by the term $\rho C$ allows to define for each type of source an equivalent heating rate in ${ }^{\circ} \mathrm{C} / \mathrm{s}$, corresponding to a monotonous and adiabatic heating process. This also facilitates comparison between the dissipative source and the thermoelastic coupling source.

\subsubsection{Thermoelastic coupling source}

For temperature variations $T$ close to the thermal equilibrium $T_{0}$ and in case of a fretting loading, considered as a non-proportional multiaxial fatigue loading, the thermoelastic source, is defined as follows:

$$
s_{\text {the }}=-T_{0} \cdot \lambda \cdot \operatorname{tr}(\dot{\sigma})
$$

where $\lambda$ is the thermal expansion coefficient.

In this case, the components of the cyclic stress tensor can be written as follows:

$$
\sigma_{i j}(t)=\sigma_{m_{i j}}+\sigma_{a_{i j}} f_{i j}(t)
$$

with $\sigma_{m}$, the mean stress tensor, $\sigma_{a}$, the stress amplitude tensor and $f_{i j}(t)$ a periodic time function such as :

$$
f_{i j}(t+\Gamma)=f_{i j}(t), \text { with } \Gamma \text {, the period and } \int_{t}^{t+\Gamma} f_{i j}(u) d u=0, \forall t
$$

In such conditions:

- The thermoelastic source is phase shifted having the same frequency spectrum as the loading

- The variation of the thermoelastic energy $w_{\text {the }}$ vanishes at the end of each complete loading cycle: 


$$
w_{\text {the }}(\Gamma)=\int_{0}^{\Gamma} s_{\text {the }} d t=-\lambda T_{0} \sigma_{a_{i i}} \int_{0}^{\Gamma} f_{i i}(u) d u=0,
$$

\subsubsection{Dissipative source}

The dissipation is always positive. Its definition $\left(d_{1}=\left(\sigma-\rho \frac{\partial \psi}{\partial \varepsilon}\right): \dot{\varepsilon}-\rho \frac{\partial \psi}{\partial \alpha} \cdot \dot{\alpha}\right)$, also suggest that the dissipated energy may be induced by both the strain rate $\dot{\varepsilon}$ and $\dot{\alpha}$, which stands for the microstructural evolution.

Lemaitre and Chaboche in [32], shows that for a viscous behavior the dissipated energy is proportional to $f_{L}^{2}$, while for a plastic behavior it is proportional to $f_{L}$.

In case of a fretting loading under partial slip conditions, the kinetics of microstructural degradation is slow for a small number of cycles and therefore, we consider a mean intrinsic dissipation per cycle $\tilde{d}_{1}$, defined as follows:

$$
\tilde{d}_{1}=N^{-1} f_{L} \int_{0}^{\Gamma} d_{1} d t
$$

$\tilde{d}_{1}$ is a positive heat source with a spectrum limited to low frequencies.

\subsection{Heat sources determination}

The partial differential equation (6) and the boundary conditions being linear, it is possible to separately study the influence of each source on the temperature fields:

$$
\theta=\theta_{\text {the }}+\theta_{d}
$$

with $\theta_{t h e}$, the temperature pattern induced by $s_{\text {the }}$ and $\theta_{d}$, the one induced by $d_{1}$.

The first step in the determination of the intensities of both heat sources, go through the estimation of the overall heat generation using a finite difference approximation of the temperature field (more details are given in the next section). Only stabilized thermal fields are considered. For the amplitude of the thermoelastic source, it is possible to extract from the thermal signal, the periodic part having the same frequency as the loading frequency and introduce it into equation (6). The second step, consist on a time-integration of the overall heat source in order to get the overall involved energy. With the thermoelestic energy, $w_{\text {the }}$, vanishing at the end of each complete cycle, it is possible then to determine the mean intrinsic dissipation per cycle.

\section{2D IMAGE PROCESSING TECHNIQUE}

As we saw in the above section, the computation of the heat sources implies different derivatives that have to be locally estimated using discrete and noisy thermal data. To reduce the amplitude of the noise while conserving as much information as possible on the thermal gradients and their 
A.R. Moustafa, B. Berthel, S. Fouvry, E. Charkaluk, International Journal of Fatigue, 2017, 95, 143.

evolution in space and time, a sliding-smoothing least-square fitting method is considered [15]. It consist on approximating the measured temperature by a periodic function based on the spectral properties of the underlying heat sources. Therefore, the approximation function becomes:

$$
\theta^{f i t}(x, y, t)=P_{1}(x, y)+P_{2}(x, y) t+P_{3}(x, y) \cos \left(2 \pi f_{L} t\right)+P_{4}(x, y) \sin \left(2 \pi f_{L} t\right)
$$

where the linear time function takes transient effects due to heat losses, dissipative heating and possible drifts in the equilibrium temperature into account. While the trigonometric functions describe the periodic part of the thermoelastic effects. The $P_{\alpha}$ functions are polynomials of degree 2 in $x$ and $y$ accounting for local spatial heterogeneities of the temperature fields.

The resolution of the smoothing problem consists then, in minimizing the following $B^{2}$ sum compared to the $P_{\alpha}$ coefficients, in a least squares sense, on a discrete smoothing window, characterized by two spatial parameters, $N_{x}$ and $N_{y}$, and one temporal parameter $N_{t}$ (Figure 5):

$$
\frac{\partial B^{2}}{\partial P_{\alpha}}=\frac{\partial}{\partial P_{\alpha}}\left[\sum_{i=-N_{x}}^{N_{x}} \sum_{j=-N_{y}}^{N_{y}} \sum_{u=-N_{t}}^{N_{t}}\left(\theta_{f i t}\left(x_{i}, y_{i}, t_{u}\right)-\theta_{\exp }(i, j, u)\right)^{2}\right]=0
$$

This system can be written as:

$$
\vec{B}=\overline{\bar{M}} \cdot \vec{P}
$$

The $M$ matrix is related to the smoothing parameters $\left(N_{x}, N_{y}\right.$ and $\left.N_{t}\right)$, the loading frequency $f_{L}$, and the time step $\Delta t$. In addition, it is symmetrical and certain terms corresponding to the sums of odd functions are null. The vector $P$, is the vector containing polynomial unknowns.

Since we perform tests with fixed loading frequencies and camera frame rates, meaning constant smoothing parameters, the $M$ matrix do not depend on the considered time and position. The advantage of such property is that one needs to calculate this matrix and its inverse only once to entirely process all the data obtained from an experiment. The system size does not require an iterative method. In this way, the specific values of the approximation function at all points, are determined as follows, which greatly reduces the computation time:

$$
\vec{P}=\overline{\overline{M^{-1}}} \cdot \vec{B}
$$

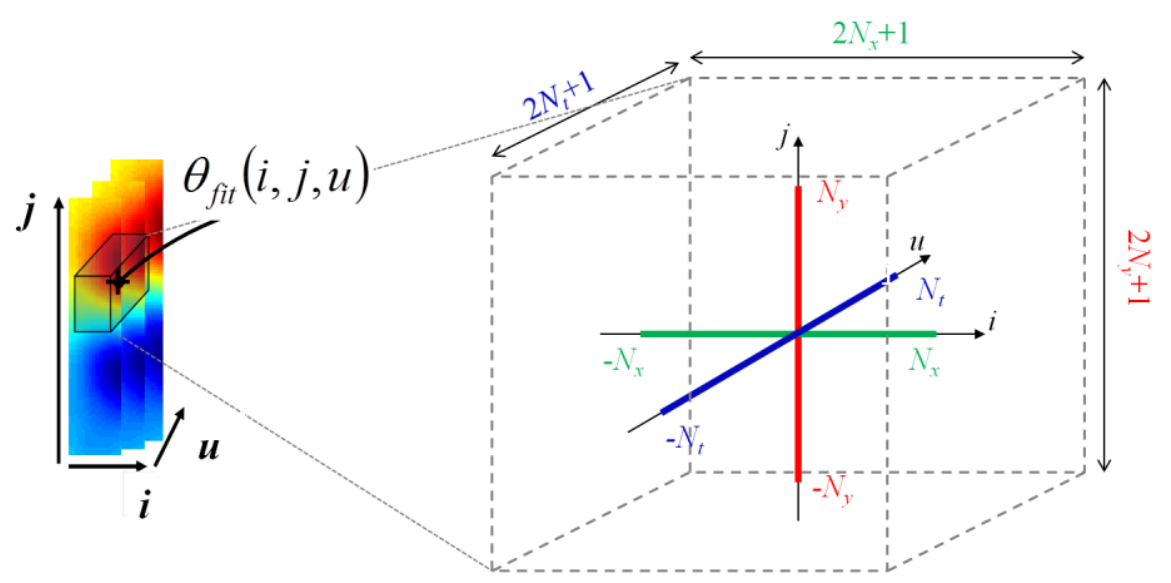

Figure 5: Discrete smoothing window. 
Once the polynomials are determined, the heat sources are estimated at the center of the smoothing window, using the definition of each type of these sources and the 2D heat diffusion equation (6):

$$
\begin{aligned}
& \frac{\tilde{d}_{1}}{\rho C}=\frac{P_{1}(0,0)}{\tau_{t h}^{2 D}}+\frac{P_{2}(0,0)}{\Delta t}-d_{f}\left(\left.\frac{1}{\Delta x^{2}} \frac{\partial^{2} P_{1}(i, j)}{\partial i^{2}}\right|_{i=0, j=0}+\left.\frac{1}{\Delta y^{2}} \frac{\partial^{2} P_{1}(i, j)}{\partial j^{2}}\right|_{i=0, j=0}\right) \\
& \frac{\Delta s_{\text {the }}}{\rho C}=2 \sqrt{\left[-\omega_{L} P_{3}(0,0)+\frac{P_{4}(0,0)}{\tau_{t h}^{2 D}}-d_{f}\left(\left.\frac{1}{\Delta x^{2}} \frac{\partial^{2} P_{4}(i, j)}{\partial i^{2}}\right|_{i=0, j=0}+\left.\frac{1}{\Delta y^{2}} \frac{\partial^{2} P_{4}(i, j)}{\partial j^{2}}\right|_{i=0, j=0}\right)\right]^{2}} \\
& {\left[+\left[\omega_{L} P_{4}(0,0)+\frac{P_{3}(0,0)}{\tau_{t h}^{2 D}}-d_{f}\left(\left.\frac{1}{\Delta x^{2}} \frac{\partial^{2} P_{3}(i, j)}{\partial i^{2}}\right|_{i=0, j=0}+\left.\frac{1}{\Delta y^{2}} \frac{\partial^{2} P_{3}(i, j)}{\partial j^{2}}\right|_{i=0, j=0}\right)\right]^{2}\right.}
\end{aligned}
$$

with $\omega_{L}=2 \pi f_{L}$ and $d_{f}=k / \rho C$.

In order to determine the spatiotemporal evolution of the heat sources, this window is moved at each point in space and time.

This method offers the advantage of working with under-sampled signals with the correct ratio between sampling frequency and loading frequency.

\section{EXPERIMENTAL RESULTS AND INTERPRETATIONS}

\subsection{Heat sources}

A first example, presented on Figure 6 (a) for $\mathrm{R}=80 \mathrm{~mm}, p_{\max }=1000 \mathrm{MPa}, q_{\max }=603 \mathrm{MPa}, f_{L}=$ $12 \mathrm{~Hz}$ and $f_{a}=20 \mathrm{~Hz}$, shows the noisy aspect of the experimental temperature fields, $\theta_{\text {exp. }}$. This can underline the necessity of processing such images in order to obtain accurate estimate of the second derivatives in space and therefore good estimate of the different heat sources. On Figure 6 (b) is presented the same field, $\theta_{f i t}$, after being locally fitted. The smoothing parameters used to process this experiment were: $N_{x}=15, N_{y}=5$ and $N_{t}=2 f_{a}+1$, and $\Delta x=0.95 \mathrm{~mm} / \mathrm{pixel}$. It can be noted the difference in size of both fields. This is due to side effects induced by the fitting process accounting for the fitting spatial window size (loss of few pixels).

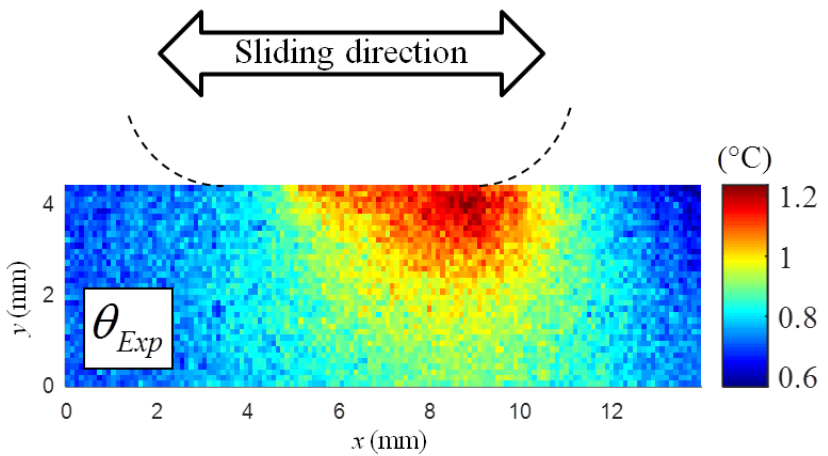

(a)

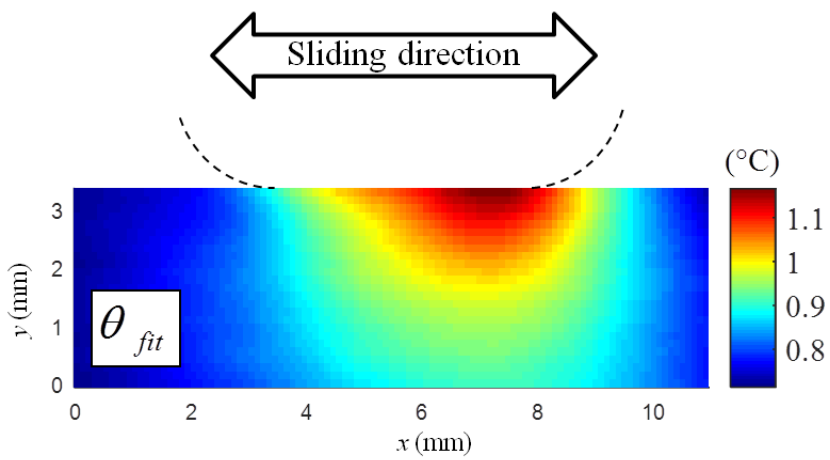

(b)

Figure 6: Temperature fields: (a) experimental and (b) fitted for a contact condition of $\mathrm{R}=80 \mathrm{~mm}$, $p_{\max }=1000 \mathrm{MPa}, q_{\max }=603 \mathrm{MPa}, a_{m}=4 \mathrm{~mm}$ and $c_{m}=2.8 \mathrm{~mm}$. 
Fields of $\Delta s_{t h e}$, corresponding to the amplitude of the thermoelastic source and $d_{1}$, the mean intrinsic dissipation per cycle for the same contact condition, are represented respectively on Figure 7 (a) and (b). It can be first observed the difference in the order of magnitude between these two sources. This reflect the difficulty in the determination of such sources. Second, both fields present heterogeneous spatial distribution with maximum values (hot spots) in the sliding areas. The asymmetry of these two hot spots can be explained by a difference in stiffness between the upper and bottom side of the tested sample and that due to the configuration of the testing device (Figure 1 (a)).

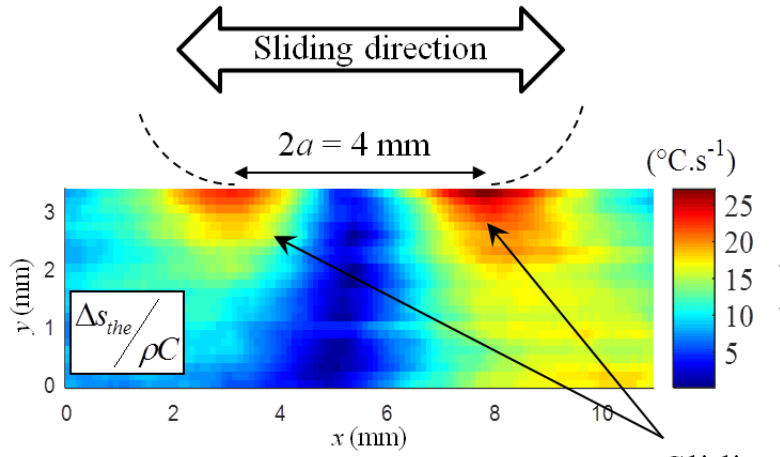

(a)

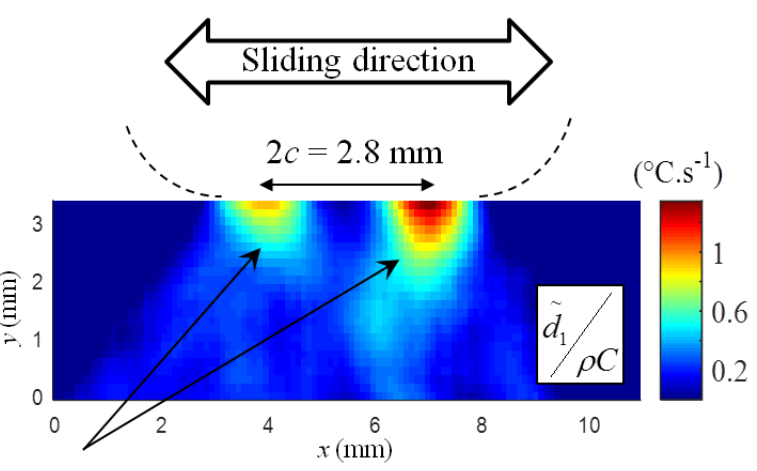

(b)

Figure 7: Fields of (a) thermoelastic amplitude and (b) mean dissipation per cycle.

In order to control the nature of the estimated heat sources, a series of numerical and experimental tests are conducted and presented in the next sections.

\subsection{Experimental control of the nature of the estimated heat sources}

\subsubsection{Temporal evolution}

The spatial heterogeneities of the estimated fields were found to be time independent for constant loading parameters $\left(p_{\max }=1000 \mathrm{MPA}, q_{\max }=603 \mathrm{MPA}, f_{L}=12 \mathrm{~Hz}\right.$ and $f_{a}=20 \mathrm{~Hz}, a_{m}=4 \mathrm{~mm}$ and $c_{m}=2.8 \mathrm{~mm}$ ), and that at least before a crack is initiated. This can be seen on Figure 8 where, for each source, are represented two fields, one after 3000 cycles (2.5 minutes) of testing and the other one after 15000 cycles (10.5 minutes).

The time independent feature of the thermoelastic source can be explained by the fact that, for constant loading parameters, the stress level and distribution stay constant unless damage occures. As for the dissipative source, the time independent feature can be related to the low kinetics of the fretting damage. 
A.R. Moustafa, B. Berthel, S. Fouvry, E. Charkaluk, International Journal of Fatigue, 2017, 95, 143.

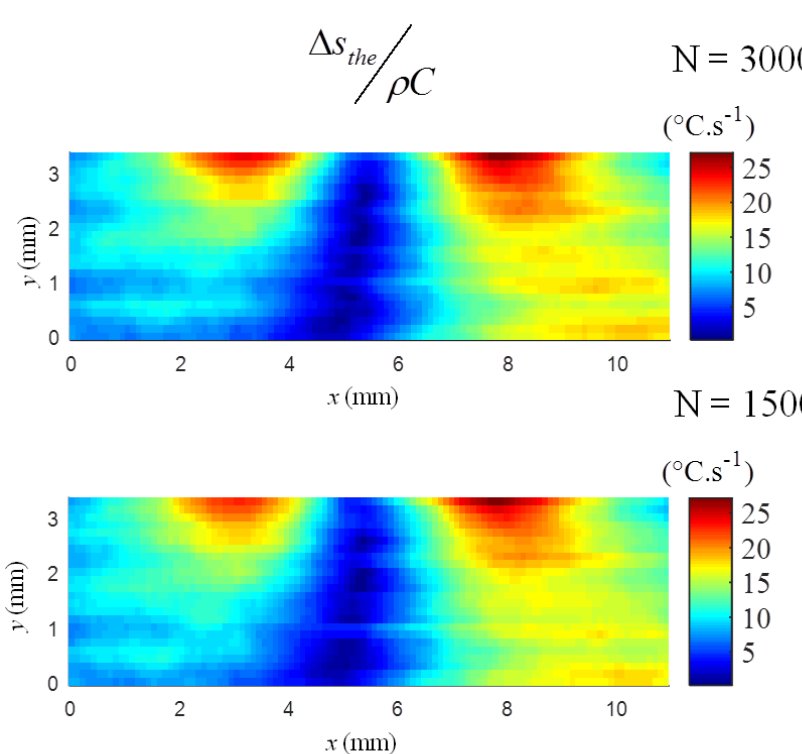

(a)
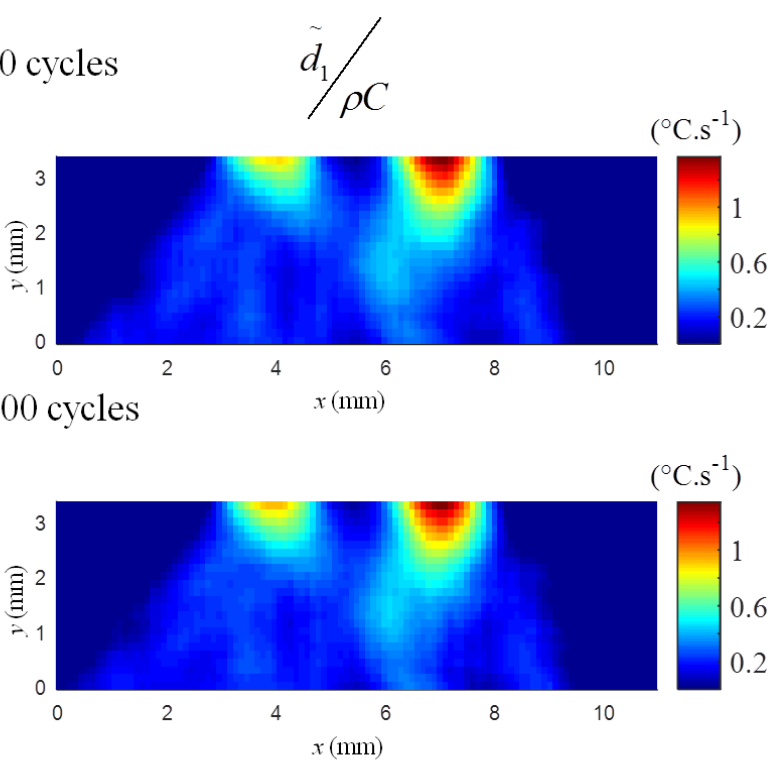

(b)

Figure 8: Fields of (a) thermoelastic amplitude and (b) mean dissipation per cycle after 3000 and 15000 cycles.

\subsubsection{Influence of the loading parameters}

The intensities of the estimetated sources were found to increase with the increase of the loading frequency and the shear stress amplitude, while the spatial heterogeneities were found to stay constant as shown on Figure 9 (a) and (b) and Figure 10 (a) and (b).
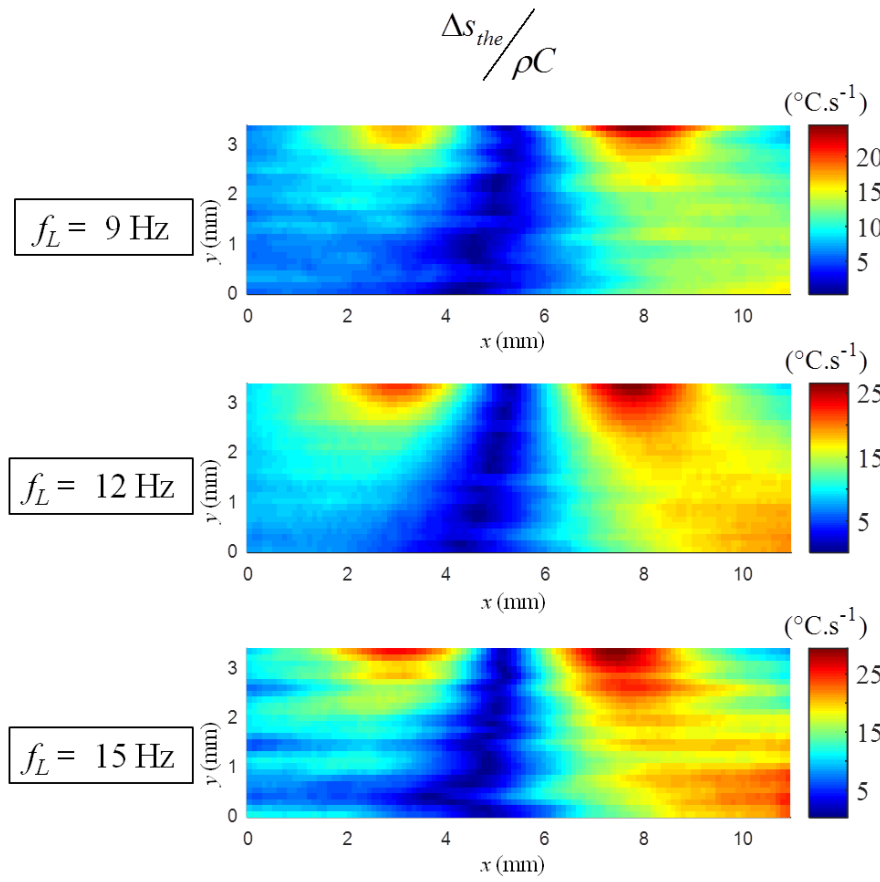

(a)
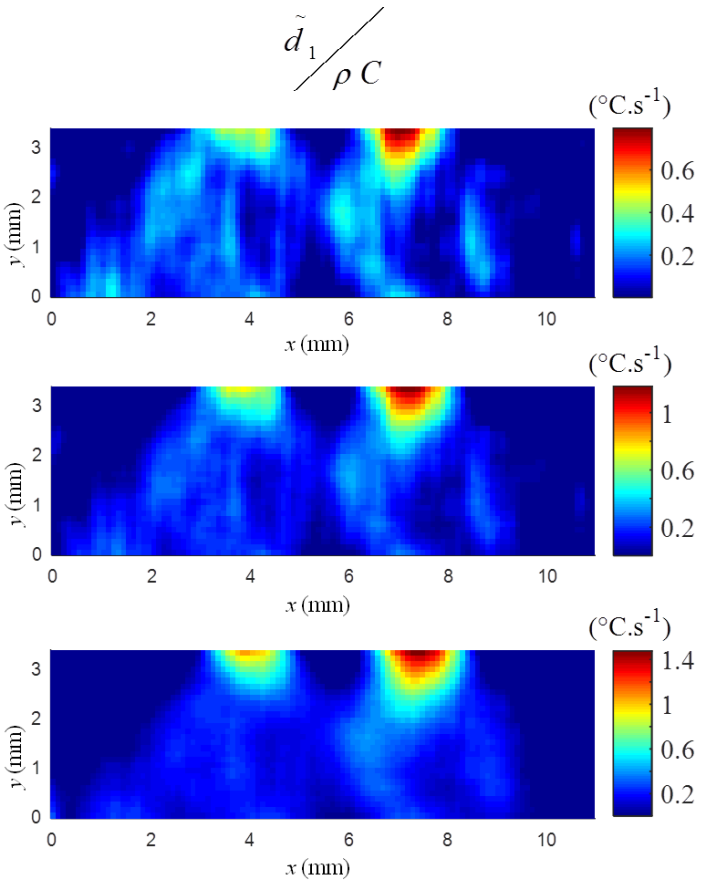

(b)

Figure 9: Fields of (a) thermoelastic amplitude and (b) mean dissipation per cycle as function of the loading frequency. $\left(\mathrm{R}=80 \mathrm{~mm}, p_{\max }=1000 \mathrm{MPa}, q_{\max }=603 \mathrm{MPa}, a_{m}=4 \mathrm{~mm}\right.$ and $\left.c_{m}=2.8 \mathrm{~mm}\right)$ 
A.R. Moustafa, B. Berthel, S. Fouvry, E. Charkaluk, International Journal of Fatigue, 2017, 95, 143.

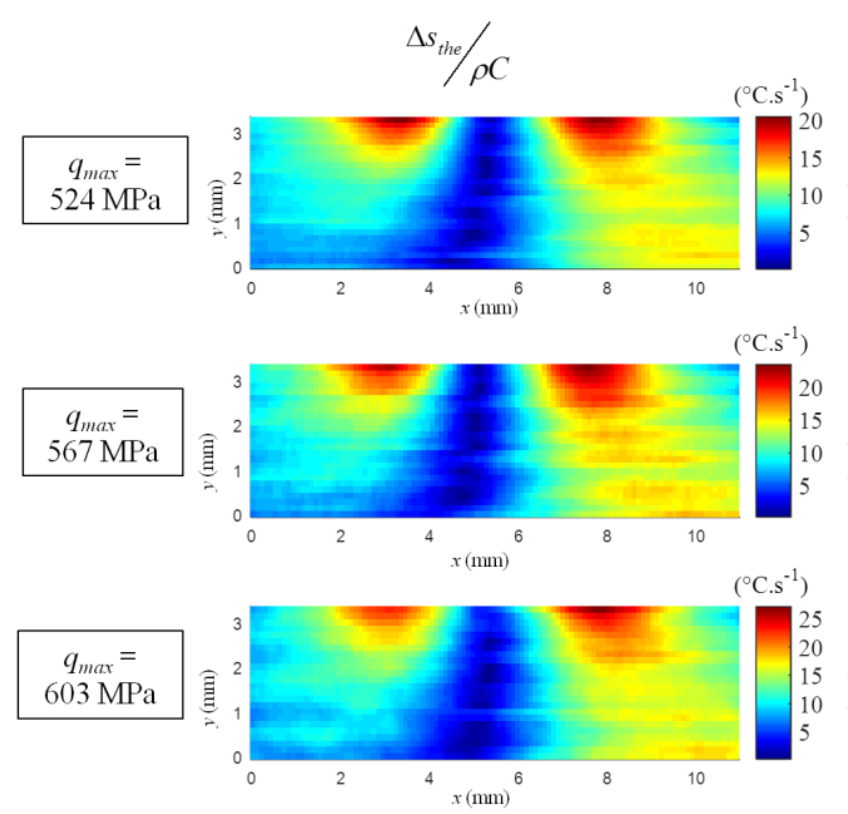

(a)
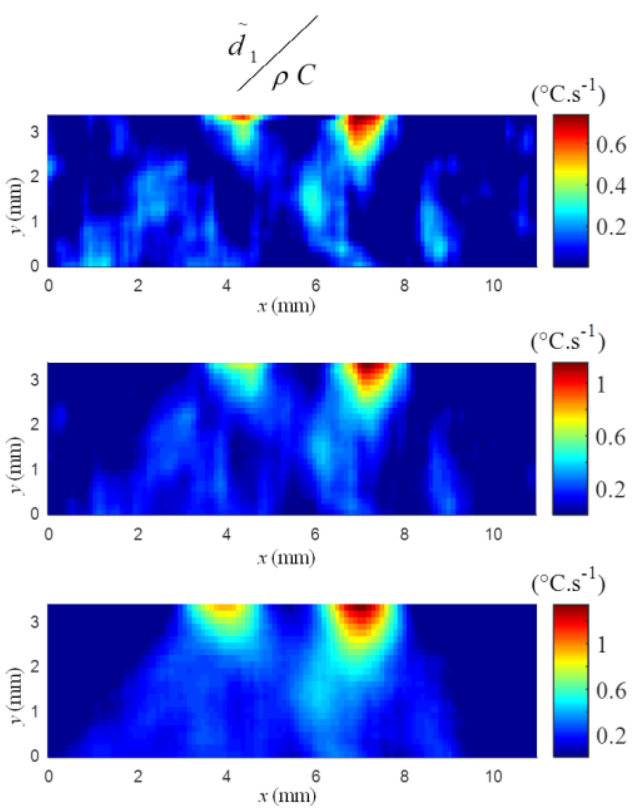

(b)

Figure 10: Fields of (a) thermoelastic amplitude and (b) mean dissipation per cycle as function the shear stress amplitude. $\left(\mathrm{R}=80 \mathrm{~mm}, p_{\max }=1000 \mathrm{MPa}, f_{L}=12 \mathrm{~Hz}\right)$

On Figure 11 (a) and (b) are plotted respectively, the evolutions of the local maxima of the estimated fields as function of different loading frequencies. In case of the thermoelastic source, the linear behavior indicate that the estimated source is in a good agreement with the theory of linear thermoelasticity (Eq. (8)). As for the intrinsic dissipation, the linear behavior is linked to the plastic behavior of the tested specimen [32].

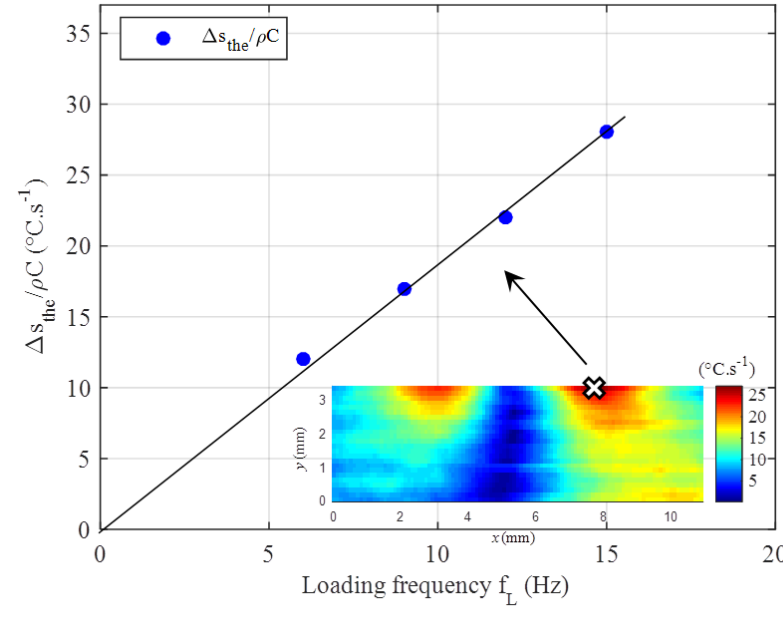

(a)

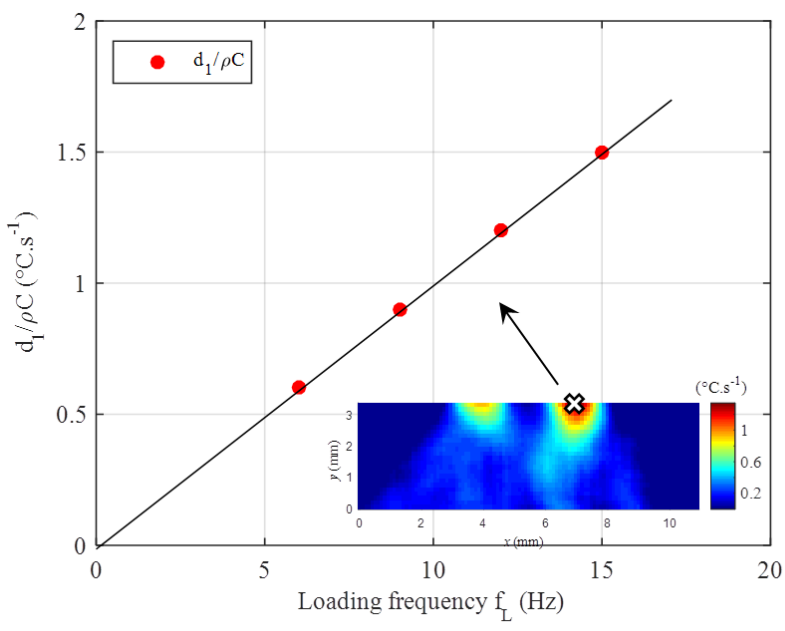

(b)

Figure 11: Evolution of the local maxima of the: (a) thermoelastic amplitude and (b) mean dissipation per cycle, as function of loading frequency.

\subsection{Numerical control of the nature of the estimated heat sources}

\subsubsection{Thermoelastic coupling}

Knowing the time evolution of the surface shear stress distribution, $q$, and the constant Hertz contact pressure distribution, $p$, allow to compute the subsurface stress fields using elastic hypothesis [3]. A 3D analytical model of linear thermoelasticity applied to non-proportional 
A.R. Moustafa, B. Berthel, S. Fouvry, E. Charkaluk, International Journal of Fatigue, 2017, 95, 143.

multiaxial cyclic loading was then developed [20]. This model allows to compute thermoelastic source fields from the knowledge of the subsurface stress fields, using the following equation:

$$
s_{\text {the }}=-T_{0} \cdot \lambda \cdot \operatorname{tr}(\dot{\sigma})=-T_{0} \cdot \lambda \cdot f_{L} \cdot \operatorname{tr}\left(\sigma_{a}\right) \cdot f^{\prime}(t)
$$

where $\lambda$ is the thermal expansion coefficient and $\sigma$ the stress tensor.

For comparison purposes, amplitude field, $\Delta s_{\text {the }}$, of the computed source was smoothed using a $2 \mathrm{D}$ median filter with a $[33 \mu \mathrm{m} 112 \mu \mathrm{m}]$ box accounting to the effect of the experimental smoothing window size, as illustrated on Figure 12 (a). On this figure, it can be observed that the spatial heterogeneities of the following fields, and their order of magnitudes are in close correlation.

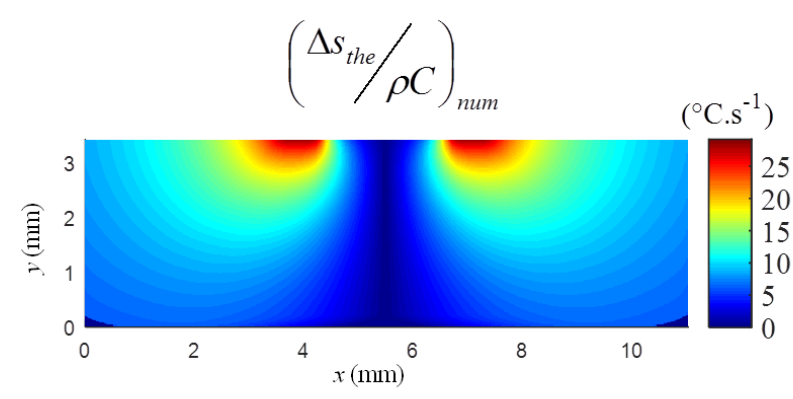

(a)

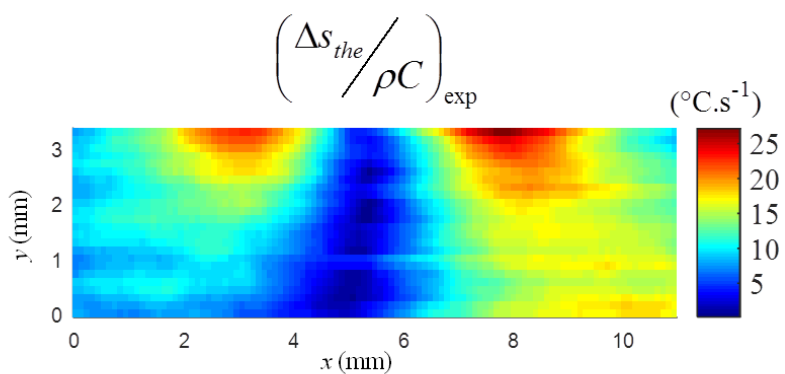

(b)

Figure 12: Fields of (a) computed thermoelastic source amplitude and (b) experimental thermoelastic source amplitude. $\left(\mathrm{R}=80 \mathrm{~mm}, p_{\max }=1000 \mathrm{MPa}, q_{\max }=603 \mathrm{MPa}, f_{L}=12 \mathrm{~Hz}\right.$ and $f_{a}=$ $20 \mathrm{~Hz}$ )

For the same cylinder radius and normal pressure, different shear stress amplitudes were tested and the local maxima of the computed thermoelastic fields amplitudes were compared to experimental data as in Figure 13.

It can be observed that the computed and experimental data undergo a linear behavior. The small differences in their order of magnitudes can be explained by the choice made on the material thermo-physical properties taken from literature (Table 2). 
A.R. Moustafa, B. Berthel, S. Fouvry, E. Charkaluk, International Journal of Fatigue, 2017, 95, 143.

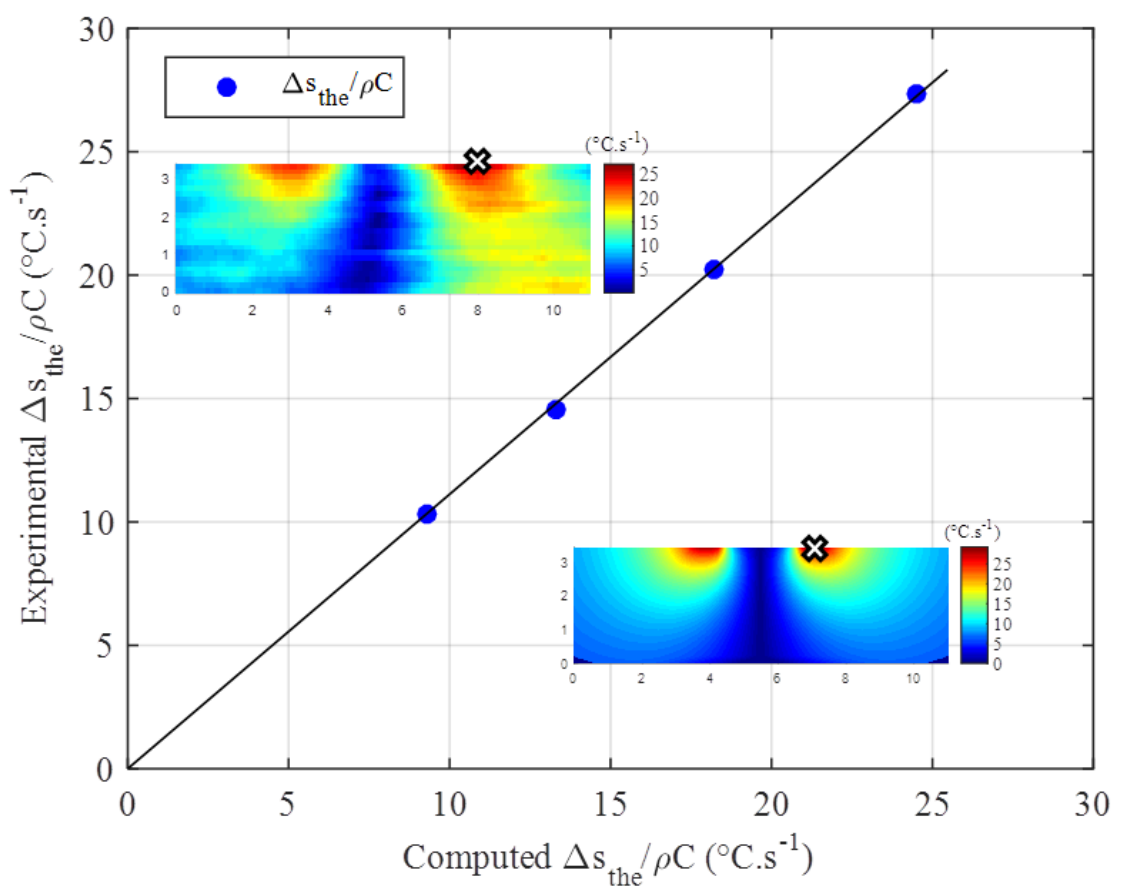

Figure 13: Experimental thermoelastic local maxima as function of computed thermoelastic local maxima.

Both the experimental and numerical results leads to the conclusion that, the estimated thermoelastic source is in a close agreement with the theory of linear thermoelasticity.

\subsubsection{Intrinsic dissipation}

The estimated dissipation fields were compared to the distribution of the multiaxial fatigue criterion of Crossland. Different studies [21], [33], showed that the Crossland criterion is well adapted to describe the crack risks under fretting loadings. This criterion is also a good indicator of microplastic behavior. The Crossland equivalent stress is defined as follows:

$$
\sigma_{C r}=\sqrt{J_{2, a}}+\alpha_{c} P_{H, \max }
$$

where the square root of the maximum amplitude of the second stress invariant is defined as follows:

$$
\sqrt{J_{2, a}}=\frac{1}{2} \max _{t_{0} \in \Gamma}\left\{\max _{t \in \Gamma}\left[\frac{1}{2}\left(\underline{\underline{S}}(t)-\underline{\underline{S}}\left(t_{0}\right)\right):\left(\underline{\underline{S}}(t)-\underline{\underline{S}}\left(t_{0}\right)\right)\right]^{1 / 2}\right\}
$$

With $\Gamma$ the period, $\underline{\underline{S}}$ the deviatoric stress and $P_{H, \max }$ the maximum value of the hydrostatic pressure throughout the history of the stress defined as follows:

$$
P_{H, \max }=\max _{t \in \Gamma}\left(\frac{1}{3} \operatorname{trace}(\underline{\underline{\sigma}}(t))\right)
$$

and,

$$
\alpha_{c}=\frac{\tau_{d}-\sigma_{d} / \sqrt{3}}{\sigma_{d} / 3}
$$

with $\tau_{d}$ the alternating shear fatigue limit and $\sigma_{d}$ the alternating bending fatigue limit. 
On Figure 14, are presented fields of the estimated mean dissipation per cycle and the Crossland equivalent stress distribution for the following condition : $R=80 \mathrm{~mm}, p_{\max }=1000 \mathrm{MPa}, q_{\max }=603$

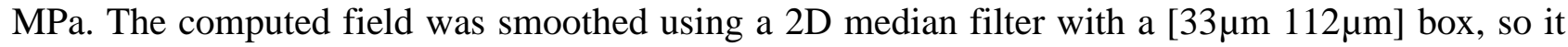
can be compared to the experimental one. With the exception of the experimental field asymmetry, it can be observed that the spatial distribution of these fields undergo a close correlation.

The local maxima of both the mean intrinsic dissipation and the Crossland equivalent stress were then compared for different contact conditions and plotted on Figure 15. It can be observed that both quantities undergo a linear behavior. Consequently, this assumes that the estimated mean dissipation can be linked to early cyclic microplasticity.

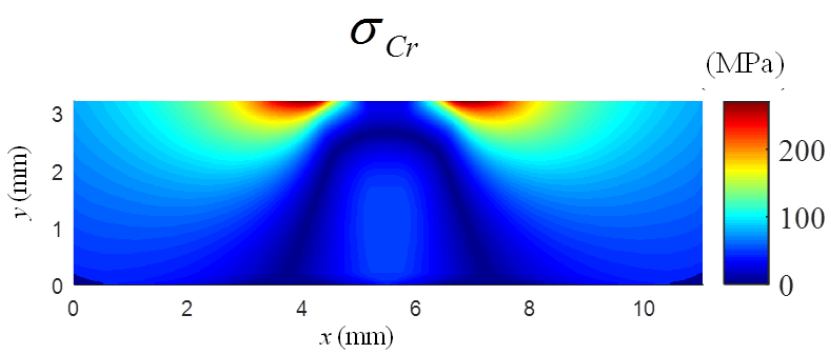

(a)

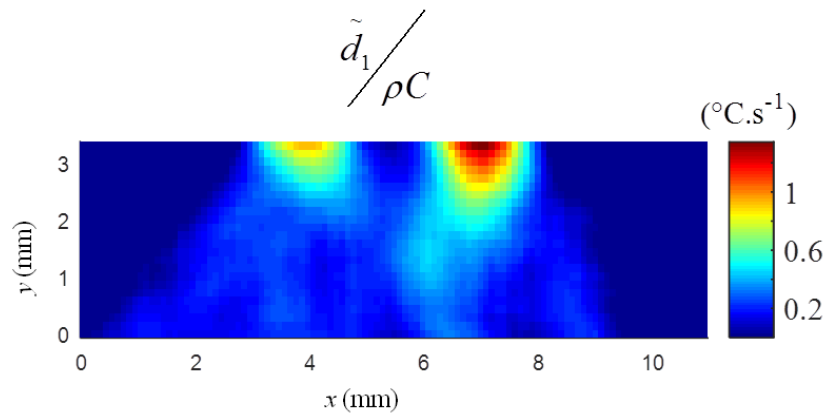

(b)

Figure 14: Fields of (a) the Crossland equivalent stress distributions and (b) the estimated mean dissipation per cycle.

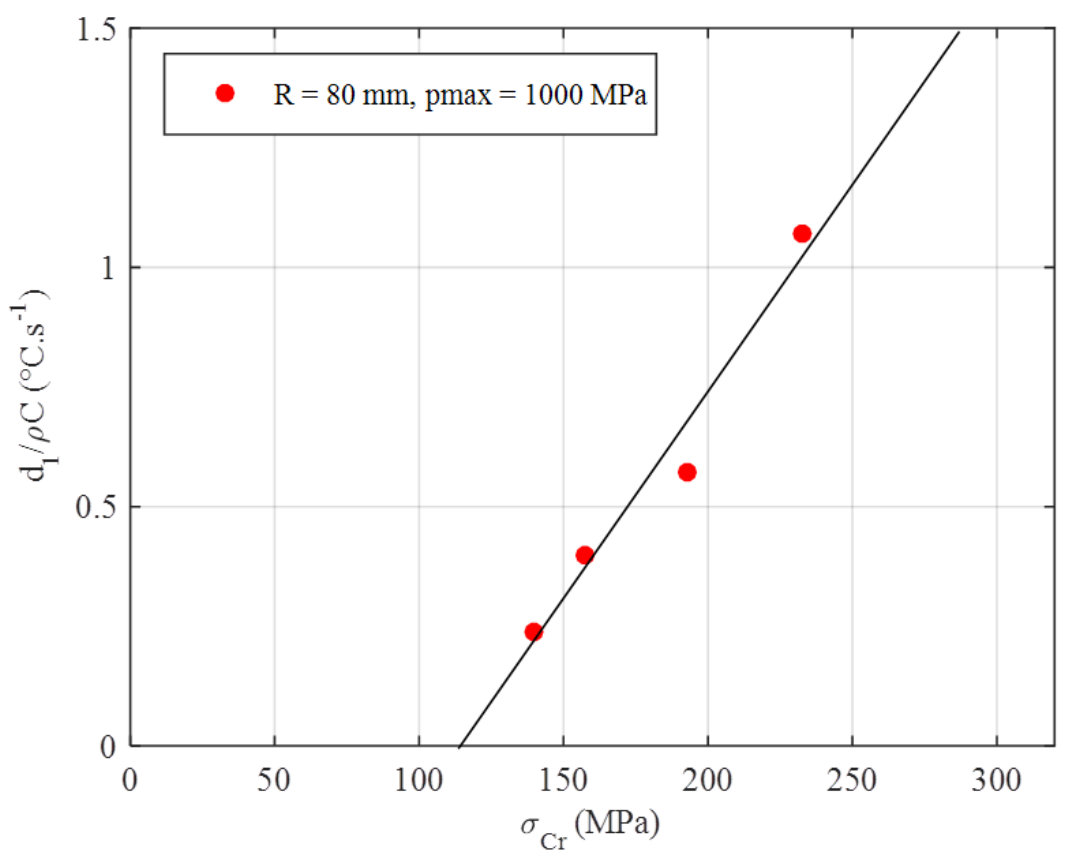

Figure 15: Maximal local evolution of the dissipative source as function of the maximal local Crossland equivalent stress.

Both experimental and numerical results leads to the conclusion that, the estimated intrinsic dissipation source reflect the onset of the plastic behavior of the tested specimen.

\subsection{Relationship between intrinsic dissipation and cyclic plastic behavior}


A.R. Moustafa, B. Berthel, S. Fouvry, E. Charkaluk, International Journal of Fatigue, 2017, 95, 143.

It was shown that the intrinsic dissipation reach a stabilized state after few cycles and that it stays constant for a low number of cycles. To study the influence of the contact stress on the mean dissipation, a test in blocks of cycles with constant maximal Hertzian pressure, $p_{\max }$, and variable shear stress amplitude was made Figure 16.

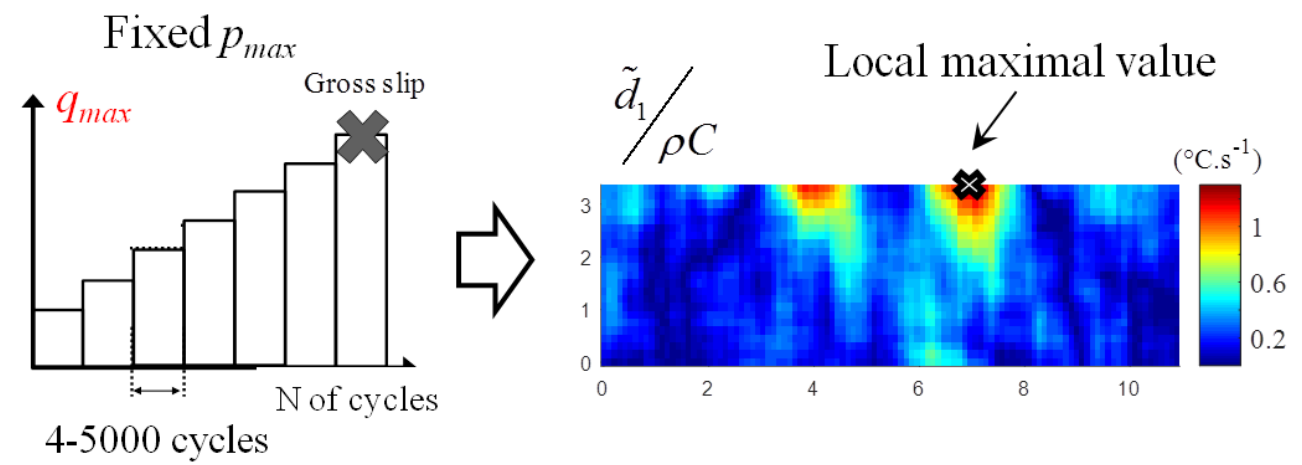

Figure 16: Schamatic illustrating a test in block of cycles.

For each block, the number of cycles was high enough (about 4000 - 5000 cycles) to reach stabilized mechanical (cycle stabilization) and thermal (temperature stabilization) conditions in order to estimate fields of the mean dissipation per cycle.

On Figure 17, are plotted the local maxima of the mean dissipation as function of the maximal shear stress amplitudes, $q_{\max }$, for each block of cycles for the following experimental condition: $R=80$ $\mathrm{mm}$ and $p_{\max }=1000 \mathrm{MPa}$.

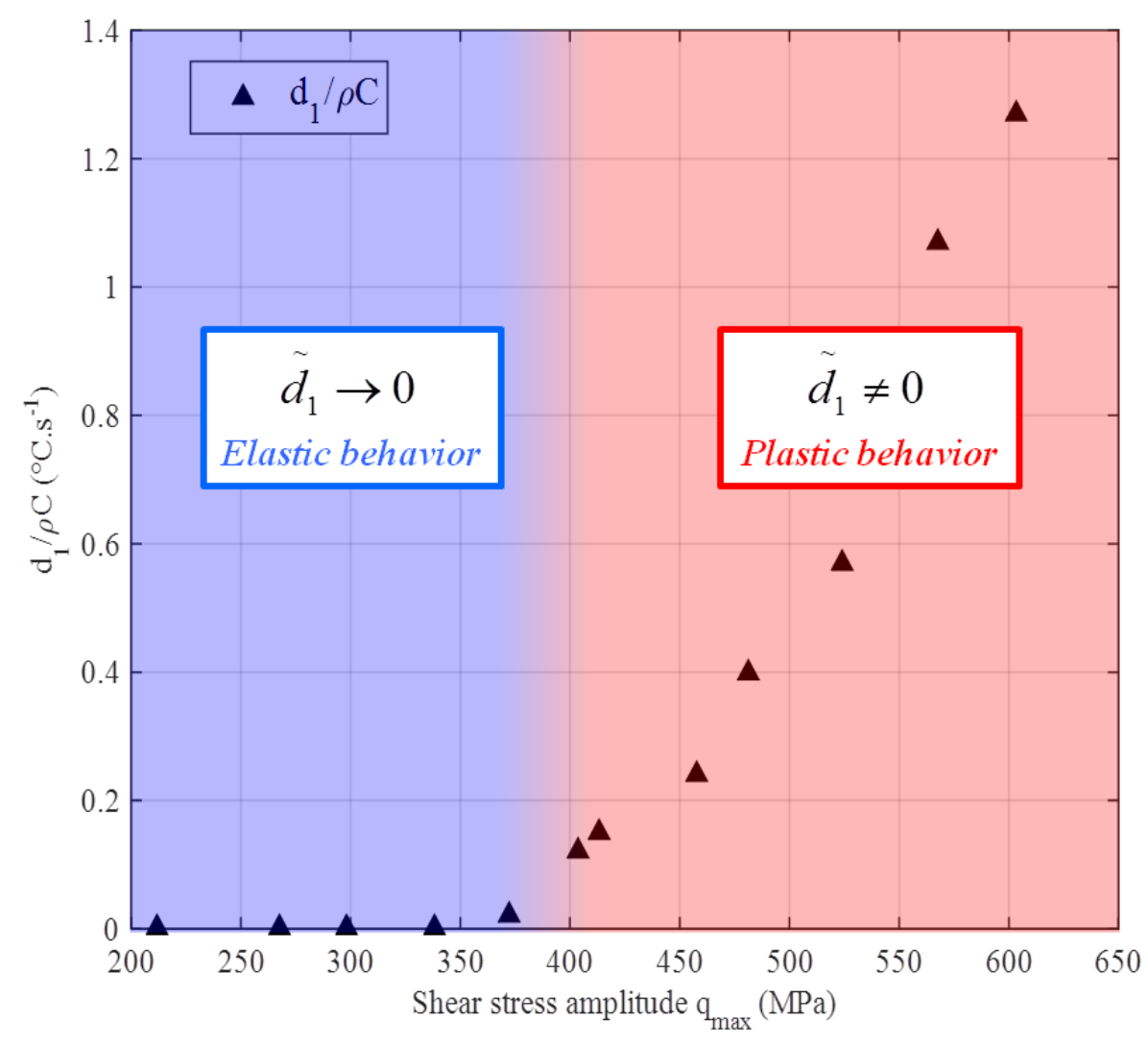

Figure 17: Local maxima of the mean dissipation as function of the maximal shear stress amplitudes, $q_{\max }$, for each block of cycles. 
A.R. Moustafa, B. Berthel, S. Fouvry, E. Charkaluk, International Journal of Fatigue, 2017, 95, 143.

The above figure underlines the presence of two dissipative regimes. A first regime with a nondissipative phase, where the specimen mainly undergo elastic deformation, and a second one, where the mean dissipation increases with the shear stress amplitude indicating a plastic behavior. This suppose the existence of a threshold shear stress value from which cyclic plasticity start to take place and this latter can be considered as the elastic shakedown threshold.

The same test was then made for the different tested conditions presented in Table 3 and the different results are presented on Figure 18. For each case, the same behavior as in Figure 17 was found. It can be concluded that the transition between the two dissipative regimes can be correlated to a threshold value from which localized microplastic deformation starts to take place.
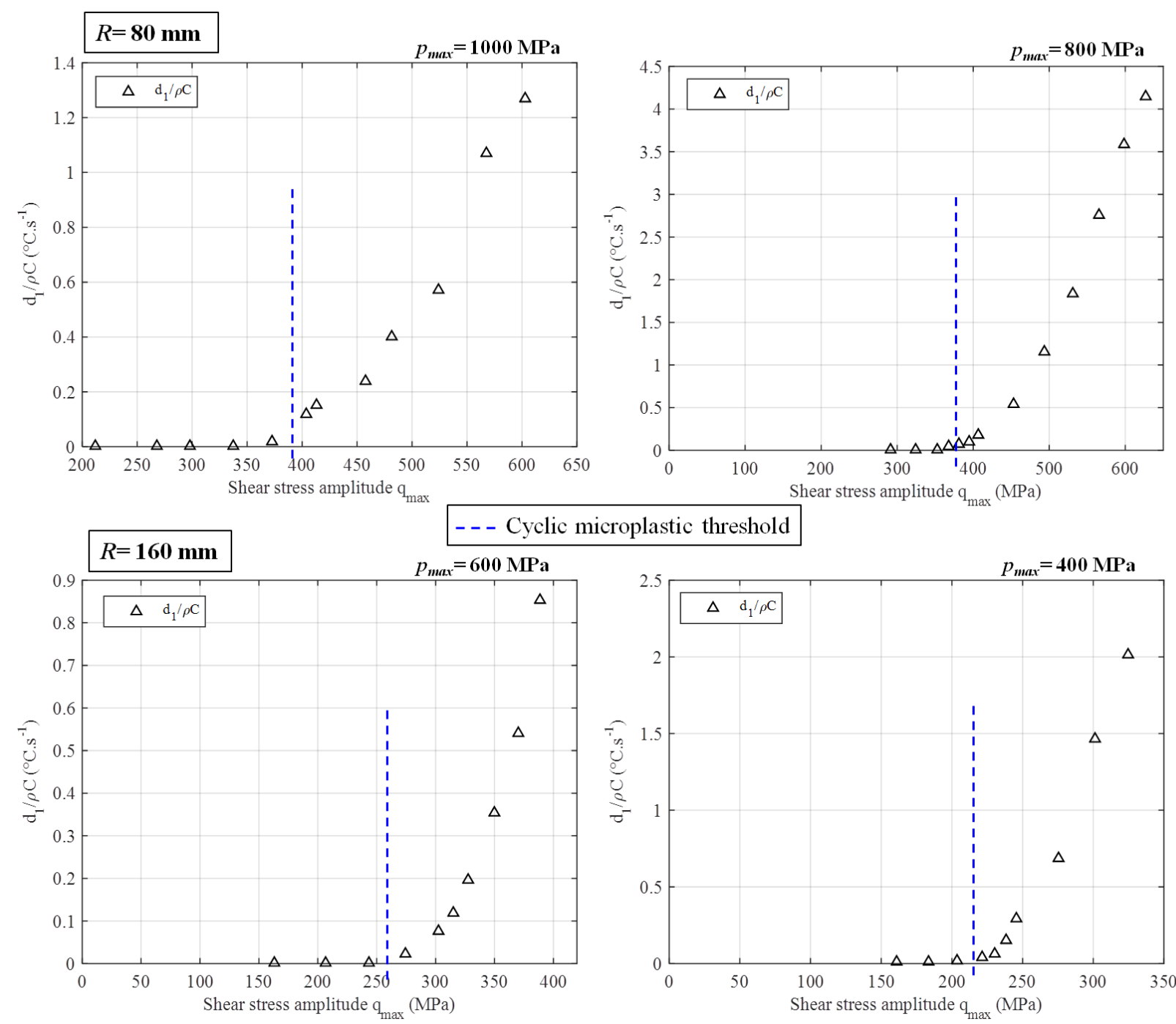

Figure 18: Local maxima of the mean dissipation as function of the maximal shear stress amplitudes, $q_{\max }$, for different contact configurations.

\subsection{Relationship between intrinsic dissipation and cracking conditions}

In order to study the link between the estimated intrinsic dissipation and the cracking conditions, a threshold value is defined as the mean value of the two first shear stress amplitudes corresponding to $\frac{\tilde{d}_{1}}{\rho C}>0$. Cracking boundaries were determined by a conventional method as in [5] and illustrated on Figure 19 and Figure 20. The following maps are known as the fretting maps and it is 
A.R. Moustafa, B. Berthel, S. Fouvry, E. Charkaluk, International Journal of Fatigue, 2017, 95, 143.

reminded that the crack initiation threshold values given by that method, are calibrated experimentally for a crack length $b=10 \mu \mathrm{m}$ and for $10^{6}$ cycles.

On these maps are also presented the boundaries obtained by thermographic measurements. It can be observed that as expected these boundaries are left-shifted compared to the crack nucleation boundaries. However, the difference between the two boundaries stays very small, which suggest that the thermal measurement provides very relevant elastic shakedown boundaries and allow us to predict the cracking conditions.

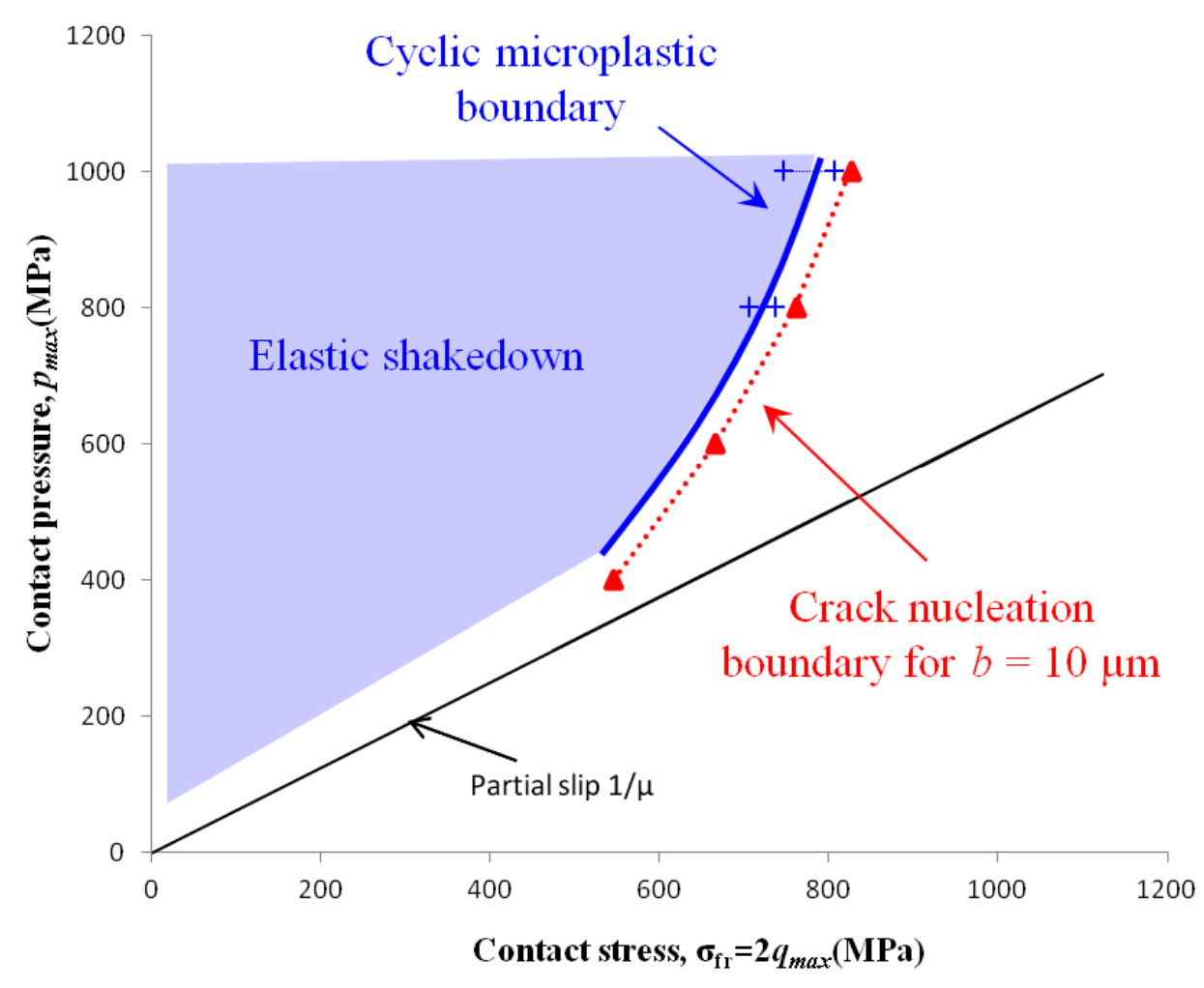

Figure 19: Fretting map and elastic shakedown boundary for $R=80 \mathrm{~mm}$. 


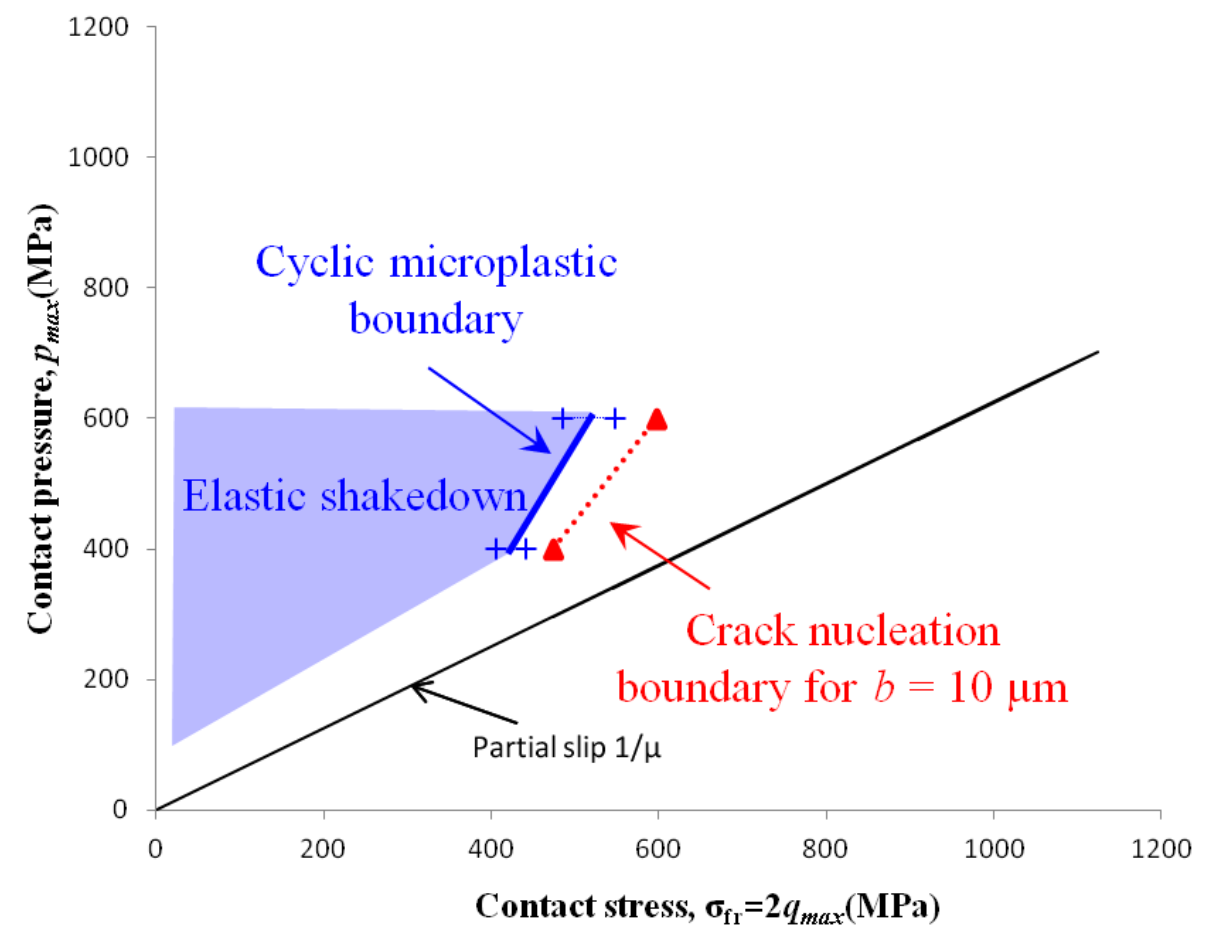

Figure 20: Fretting map and elastic shakedown boundary for $R=160 \mathrm{~mm}$.

\section{CONCLUSION}

In this paper, the thermomechanical framework responsible for the interpretation of a fretting test and the definition of the heat diffusion equation along with the assumptions made to simplify the diffusion problem were first presented. A 2D image processing technique was then introduced. This technique relies on a local spatiotemporal smoothing of the experimental temperature fields to estimate then, via the heat equation, fields of mean intrinsic dissipation per cycle and thermoelastic amplitudes. It was shown that, this method is capable of detecting the intensities and the spatial distributions of these sources.

The experimental results showed that the above method is able to estimate thermoelastic amplitude fields in a good agreement with the theory of linear thermoelasticity, and mean intrinsic dissipation per cycle fields reflecting localized microplastic deformation. The spatial distributions of the different fields showed a strong localization around the contact in the sliding areas.

The study of the maximal local evolution of the intrinsic dissipation as function of the shear stress amplitude, underlined the presence of a non-dissipative regime, where the specimen mainly undergo elastic deformation and a dissipative regime where plastic deformation takes place. The transition between these two regimes was then coupled with the local elastic shakedown boundary.

This work underlined the great potential of infrared thermography to accurately detect localized microplasticity responsible of initiating a fretting crack. The amount of information provided by such technique can be of great interest for the development of new behavioral models. The thermoelastic coupling data can be related to state equations, while dissipation data can be associated with evolution equations. Such thermomechanical approach should enhance the overall understanding and identification of the damage mechanisms in relation to microstructure properties. It could also give rise to new criteria for material characterization and structure design. 
A.R. Moustafa, B. Berthel, S. Fouvry, E. Charkaluk, International Journal of Fatigue, 2017, 95, 143.

\section{Acknowledgements}

The authors would like to thank The ANR (Agence Nationale de la Recherche) for funding this project. The authors, members of LTDS, would also like to warmly thank the FAST3D project members for the fruitful and animated scientific discussions.

\section{REFERENCES}

[1] D. Hoeppner, V. Chandrasekarah, and C. Elliott, Fretting fatigue: current technology and practices. American Society for Testing Materials, West Conshohocken, USA, 2000.

[2] R. B. Waterhouse, "Fretting Fatigue," ESIS Publ., 1981.

[3] D. a. Hills, "Mechanics of fretting fatigue," Wear, vol. 175, no. 1-2, pp. 107-113, Jun. 1994.

[4] H. Proudhon, S. Fouvry, and J. Buffiere, "A fretting crack initiation prediction taking into account the surface roughness and the crack nucleation process volume," Int. J. Fatigue, vol. 27, no. 5, pp. 569-579, May 2005.

[5] H. Proudhon, S. Fouvry, and G. Yantio, "Determination and prediction of the fretting crack initiation: introduction of the $(\mathrm{P}, \mathrm{Q}, \mathrm{N})$ representation and definition of a variable process volume," Int. J. Fatigue, vol. 28, no. 7, pp. 707-713, Jul. 2006.

[6] K. L. Johnson, Contact mechanics, Cambridge. Cambridge, 1985.

[7] M. P. Szolwinski and T. N. Farris, "Mechanics of fretting fatigue crack formation," Wear, vol. 198, no. 1-2, pp. 93-107, 1996.

[8] C. Petiot, L. Vincent, K. D. Van, N. Maouche, J. Foulquier, and B. Journet, "An analysis of fretting-fatigue failure combined with numerical calculations to predict crack nucleation," Wear, vol. 183, pp. 101-111, 1995.

[9] S. Fouvry, P. Kapsa, F. Sidoroff, and L. Vincent, "Identification of the characteristic length scale for fatigue cracking in fretting contacts," J. Phys. IV Fr., vol. 8, pp. 66-159, 1998.

[10] J. A. Araujo and D. Nowell, "The effect of rapidly varying contact stress fields on fretting fatigue," Int. J. Fatigue, vol. 24, no. 7, pp. 763-775, 2002.

[11] M. Alquezar, V. Arrieta, a. Constantinescu, L. Flandi, M. H. Maitournam, and P. Wackers, "Computational fretting fatigue maps for different plasticity models," Fatigue Fract. Eng. Mater. Struct., vol. 37, no. 4, pp. 446-461, 2014.

[12] J. M. Ambrico and M. R. Begley, "Plasticity in fretting contact," J. Mech. Phys. Solids, vol. 48, pp. 2391-2417, 2000.

[13] J. M. Ambrico and M. R. Begley, "Role of macroscopic plastic deformation in fretting fatigue life predictions," Int. J. Fatigue, vol. 23, no. 2, pp. 121-128, 2001.

[14] B. Berthel, B. Wattrisse, a. Chrysochoos, and a. Galtier, "Thermographic Analysis of Fatigue Dissipation Properties of Steel Sheets,” Strain, vol. 43, no. 3, pp. 273-279, Aug. 2007. 
A.R. Moustafa, B. Berthel, S. Fouvry, E. Charkaluk, International Journal of Fatigue, 2017, 95, 143.

[15] T. Boulanger, A. Chrysochoos, C. Mabru, and A. Galtier, "Analysis of heat sources induced by fatigue loading," Fatigue Damage Mater., vol. 40, 2003.

[16] E. Charkaluk and A. Constantinescu, "Dissipative aspects in high cycle fatigue," Mech. Mater., vol. 41, no. 5, pp. 483-494, May 2009.

[17] M. P. Luong, "Infrared thermographic scanning of fatigue in metals," Nucl. Eng. Des., vol. 158, pp. 363-376, 1995.

[18] U. Landman, W. D. Luedtke, and E. M. Ringer, "Molecular Dynamics Simulations of Adhesive Contact Formation and Friction," in Fundamentals of Friction: Macroscopic and Microscopic Processes, I. L. Singer and H. M. Pollock, Eds. Dordrecht: Kluwer Academic Publishers, 1993, pp. 463-510.

[19] D. A. Rigney and J. P. Hirth, "Plastic deformation and sliding friction of metals," Wear, vol. 53, no. 2, pp. 345-370, 1979.

[20] B. Berthel, A. R. Moustafa, E. Charkaluk, and S. Fouvry, "Crack nucleation threshold under fretting loading by a thermal method," Tribol. Int., vol. 76, pp. 35-44, 2014.

[21] S. Fouvry, H. Gallien, and B. Berthel, "From uni- to multi-axial fretting-fatigue crack nucleation: Development of a stress-gradient-dependent critical distance approach," Int. J. Fatigue, vol. 62, pp. 194-209, May 2014.

[22] S. Munoz, H. Proudhon, J. Dominguez, and S. Fouvry, "Prediction of the crack extension under fretting wear loading conditions," Int. J. Fatigue, vol. 28, no. 12, pp. 1769-1779, Dec. 2006.

[23] G. Gaussorgues and S. Chomet, Infrared Thermography. London: Chapman and Hall, 1994.

[24] V. Honorat, S. Moreau, J.-M. Muracciole, B. Wattrisse, and a. Chrysochoos, "Calorimetric analysis of polymer behaviour using a pixel calibration of an IRFPA camera," Quant. Infrared Thermogr. J., vol. 2, no. 2, pp. 153-171, Dec. 2005.

[25] B. Jähne, Digital Image Processing. Springer Berlin Heidelberg, 2005.

[26] P. Germain, Cours de Mécanique des Milieux Continus, T.I - Théorie générale. Masson \& Cie, 1973.

[27] P. Germain, "Thermodynamique des milieux continus," Congrés de Mécanique de Poitiers, Poitiers, 1973.

[28] F. Sidoroff, "On the formulation of plasticity and viscoplasticity with internal variables," Arch. Mech. Stosow., vol. 5-7, pp. 807-819, 1975.

[29] J. L. Chaboche, "Description phénoménologique de la viscoplasticité cyclique avec endommagement," Université Pierre et Marie Curie, Paris 6, 1978.

[30] P. Germain, Q. S. Nguyen, and P. Suquet, "Continuum Thermodynamics," J. Appl. Mech., vol. 50, pp. 1010-1020, 2009. 
A.R. Moustafa, B. Berthel, S. Fouvry, E. Charkaluk, International Journal of Fatigue, 2017, 95, 143.

[31] A. Chrysochoos and H. Louche, "An infrared image processing to analyse the calorific effects accompanying strain localisation," Int. J. Eng. Sci., vol. 38, pp. 1759-1788, 2000.

[32] J. Lemaitre and J. L. Chaboche, Mechanics of solid materials. Cambridge University Press, 1990.

[33] R. Amargier, S. Fouvry, L. Chambon, C. Schwob, and C. Poupon, "Stress gradient effect on crack initiation in fretting using a multiaxial fatigue framework," Int. J. Fatigue, vol. 32, no. 12, pp. 1904-1912, Dec. 2010. 